\title{
المعربات في القرآن الكريم (دراسة تحليلة تاريخية و الدلالية)
}

Chaterina P. Doni, Sunarti Muksin.

Sastra Arab, Fakultas Ilmu Budaya - UMG

$$
\text { تجريد البحث }
$$

هذا البحث يتكلم عن "المعربات في القرآن الكريم (دراسة تحليلة تاريخية و الدلالية". و هذات الدات

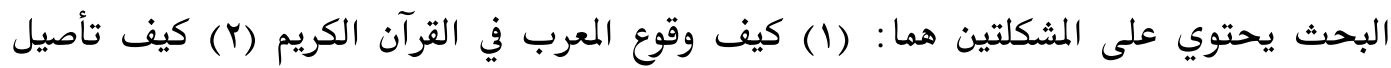

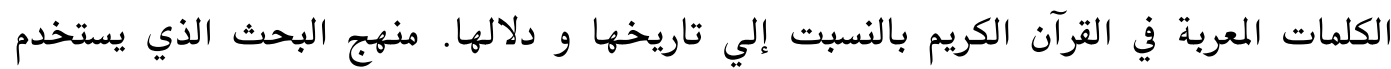

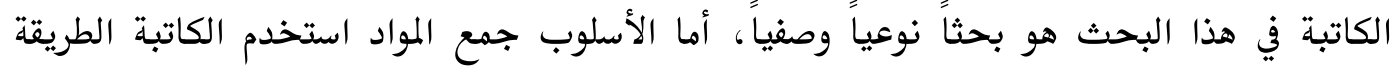

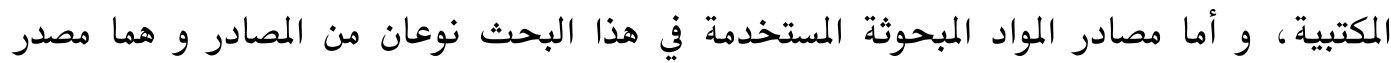

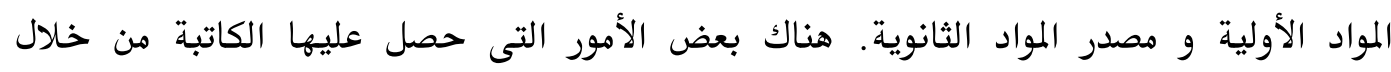

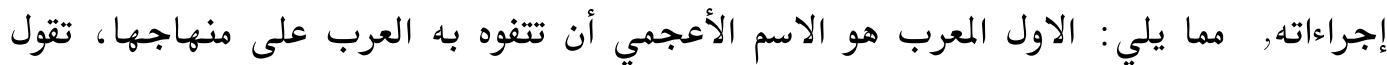

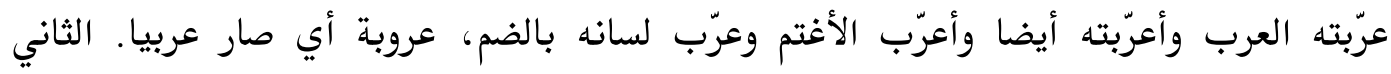

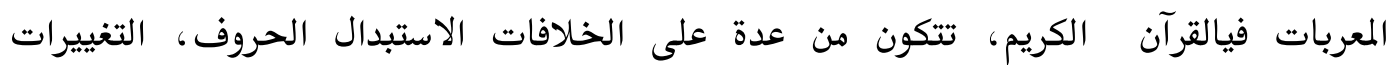

$$
\text { حركات، حذف حروف. }
$$

$$
\text { الكلمات الرئيسية: المعربات، القرآن، ، تاريخية، دلالية }
$$

القرآن هو معجزة الاسلام الخالدة التى يزيدها التقدم العلمى إلاّ رسوخا فى الإعجاز،

انزله الله على رسولنا محمد صلي الله عليه و سلم ليخرج الناس من الظلمات الى النور، ويهديهم الى الصراط المستقيم، فكان صلوات اللّه وسلامه عليه يبلغه لصحابته و هم عرب خلّّ في فيفهمونه بسليقتهم، واذا التبس عليهم فهم آية من آيات سألوا رسول الله صلى الله عليه وسلم.ا لذا لقد وجب على جميع المسلمين لقراءة القرآن و يتفقه على جميع العلوم فيه، كعلوم الشريعة، و الاحكام و الفقه و علوم الذى يتعلق باللغته و هي سيبحث الباحث في هذه الرسالة و غيرها، لحصل الى التجنب الشرود من طرقه. امناع القطان، مباحث في علوم القرآن، (مكتبة وهبة، قاهرة: VV.r) ص •

\section{'A Jamiy, Jurnal Bahasa dan Sastra Arab} Volume 06, No. 2, September 2017 


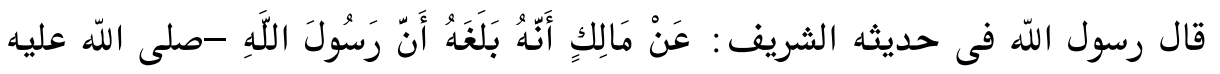

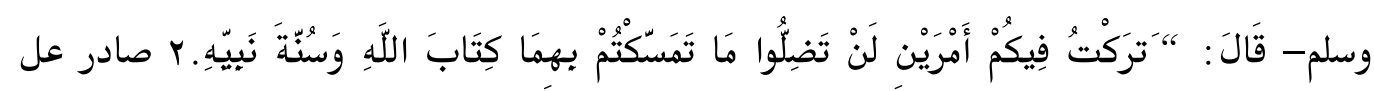

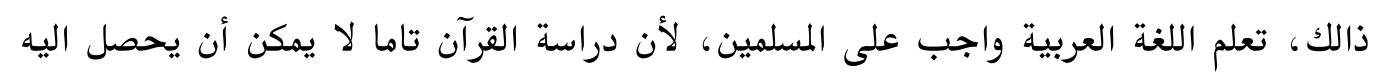
إلا إذا أتقن علوم الغة العربية فلا أحد ينكر أن العرب في جاهليتهم كانوا على اتصال بالأهم المجاورة لهم كالفرس

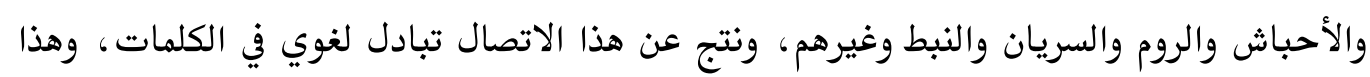

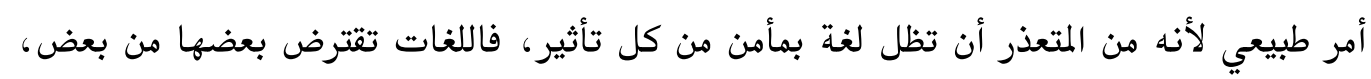

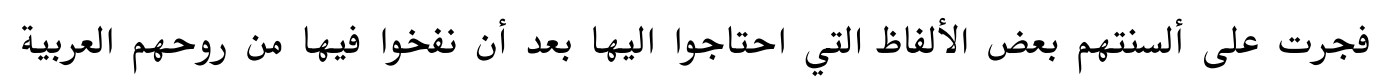

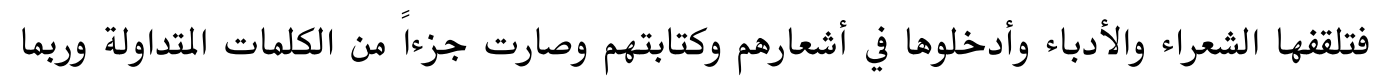
نسوا أصلها.

نزل القرآن الكريم بلغة العرب جميعا، ومعلوم أن علماء اللغة أجمعوا أن لغة الشعر

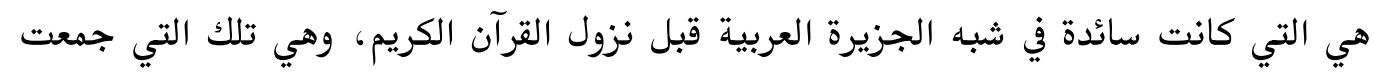

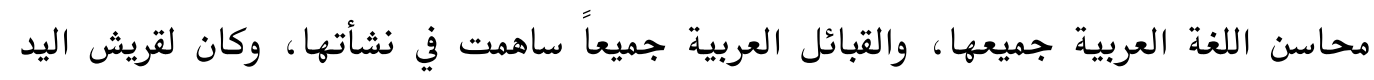
الطولى في تهذيب لغة العرب وتوحيد لهجاتهم في لغة واحدة كانت ميداناً للتنافس بين الأدباء والشعراء من مختلف القبائل.ب

وجاء القران الكريم بلسان العرب، كقول تعالى : "بلسان عربي مبين"؛ معناها "هذا

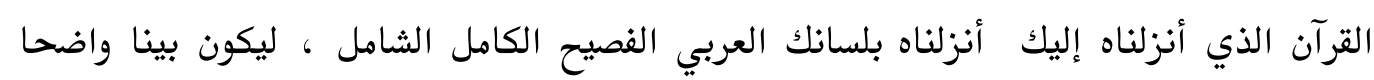

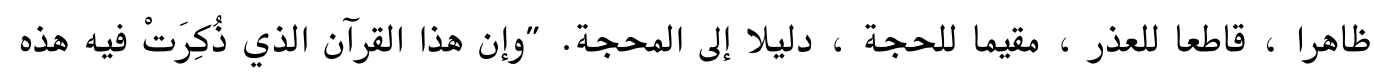

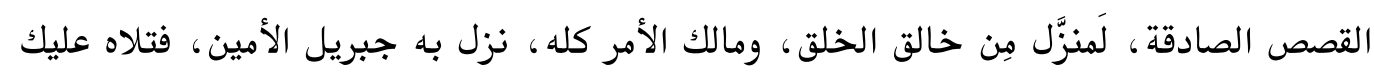

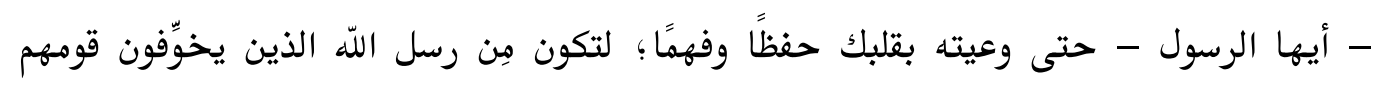

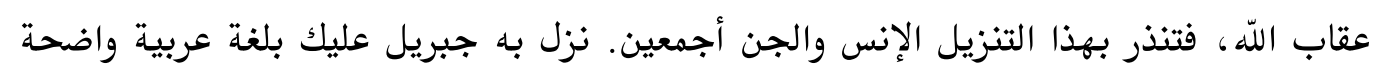

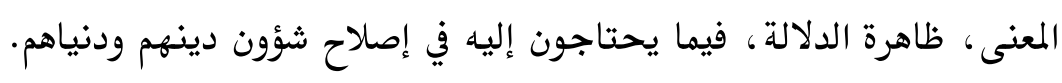

\footnotetext{
r r احديث أربعين ، سلسلة تعليم اللغة العربية، (المملكة : 1990) ص عا

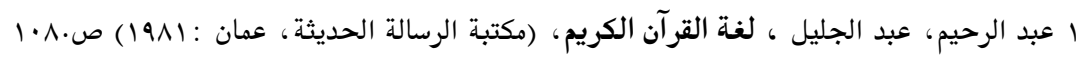

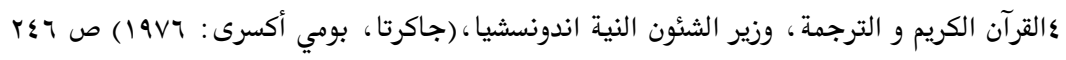

\section{'A Jamiy, Jurnal Bahasa dan Sastra Arab}

Volume 06, No. 2, September 2017 


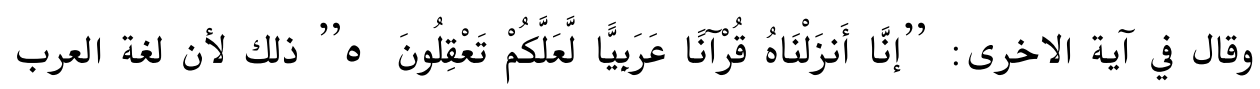

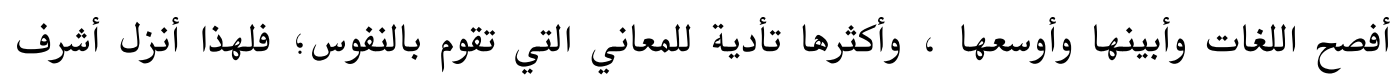

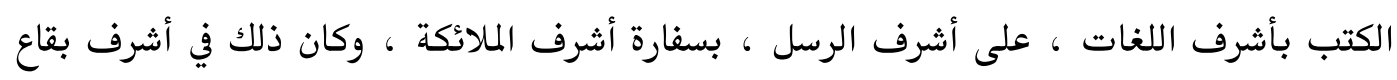

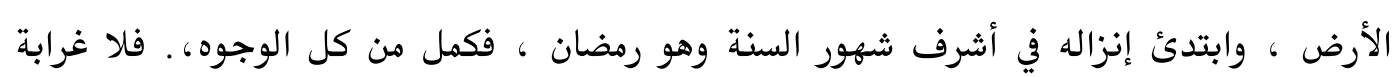

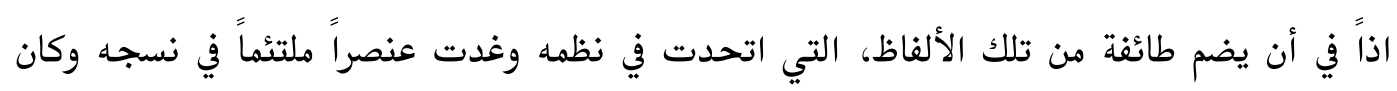

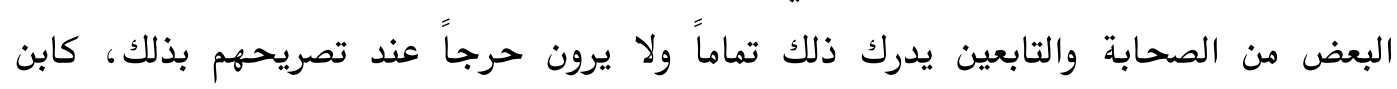

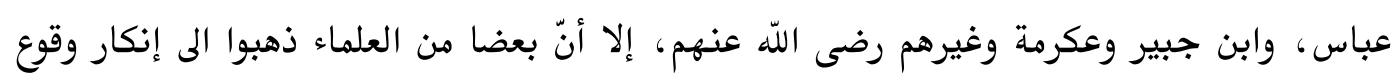

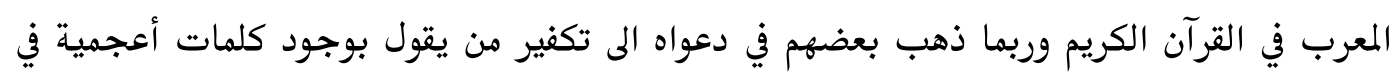

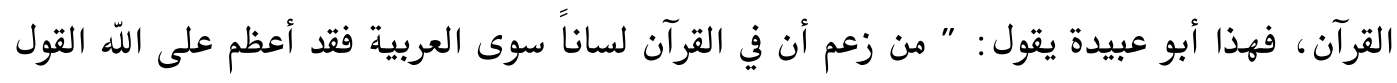

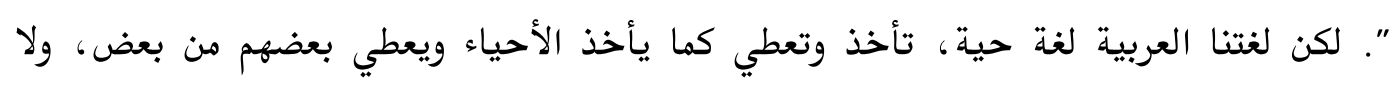

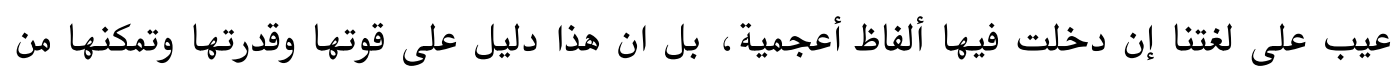
صهر تلك الألفاظ الأعجمية وتطويعها لخدمة المعرفة الشاملة. ترجع الغة العربية إلى فصيلة الغات السامية , ويطلق اسم الغة السامية على لغة هذه

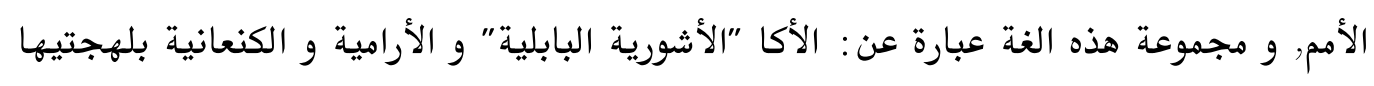

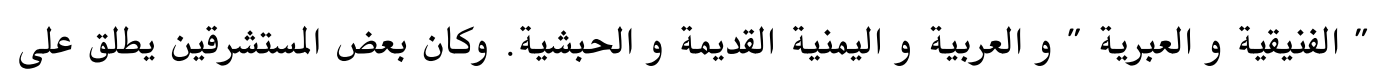

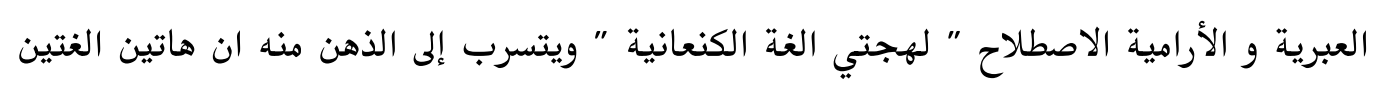

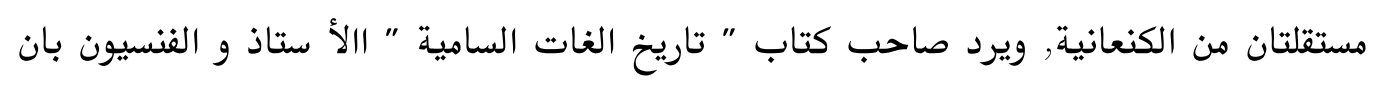
هذا خطا الأن البريين هم من بني إسرايل وغيرهم قد جاعوا بلتهم من موطنهم الأصلي, ولم

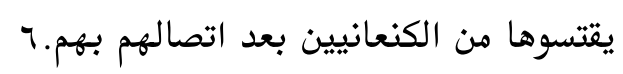
اللغة العربية ذات أهمية قصوى لدى المسلمين، فهي لغة مقدسة لغة القرآن، ولا تتم

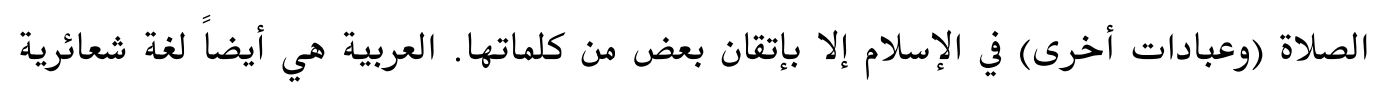

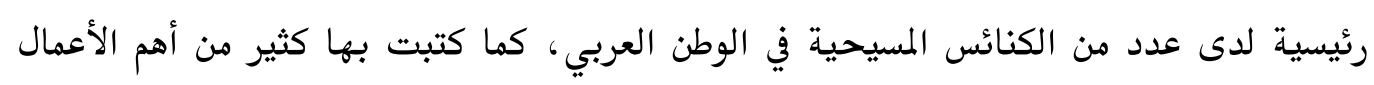
الدينية والفكرية اليهودية في العصور الوسطى. لدئ.

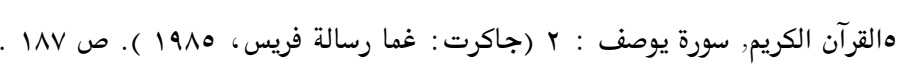

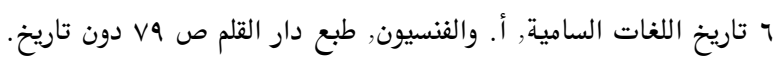

\section{'A Jamiy, Jurnal Bahasa dan Sastra Arab Volume 06, No. 2, September 2017}


إنّ ما يعنينا في هذا البحث هو الوقوف على الرأي القائل بوجود المعرّب في القرآن الكريم

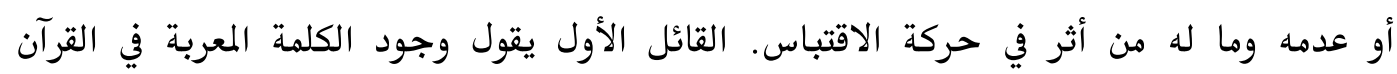
وادلتهم، و الثاني ينكروا بوجود الكلمة المعربة في القرآن وادلتهم. ويختص هذا البحث بتقديم صورة واضحة بوقوع المعرّب في القرآن الكريم واختلا العلماء

\section{1. تعريف المعرب و مرادفها}

قال ابن مذظور في لسان العرب:" وتعريب الاسم الأعجمي أن تتفوه به العرب على ألى

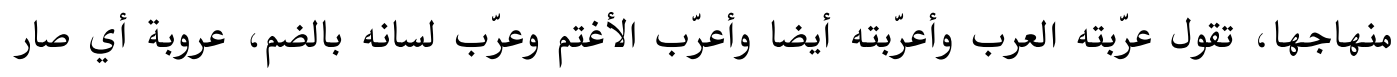

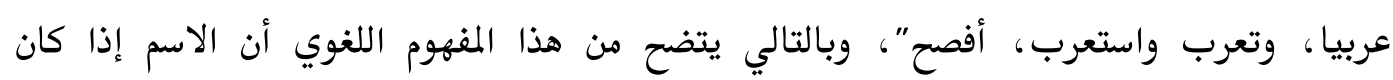

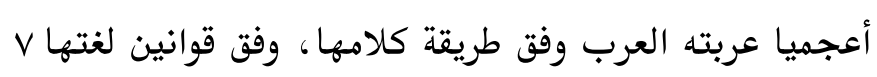

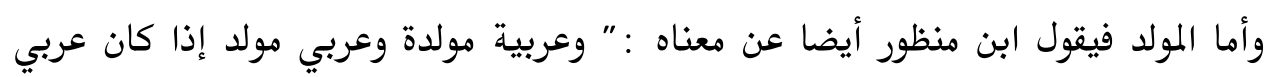

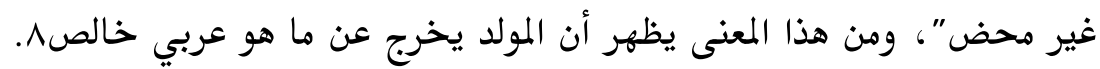
جاء في القاموس المطول للغة العربية أن الدخيل هو : " كل كلمة أدخلت في كلام العرب

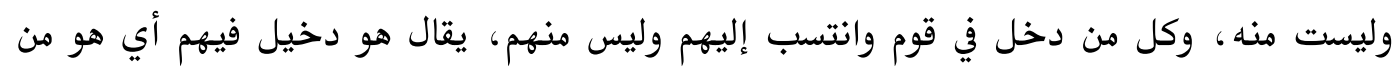

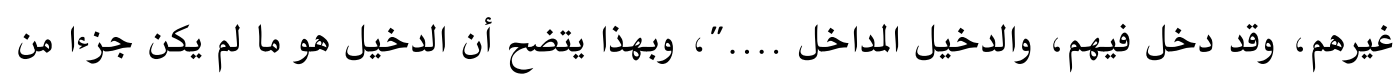
أي محيط ينتسب إليه ولا علاقة له بهه

عرف السيوطي المعرب هو ما استعملته العرب من الألفاظ الموضوعة لمعان في غير لغتها،

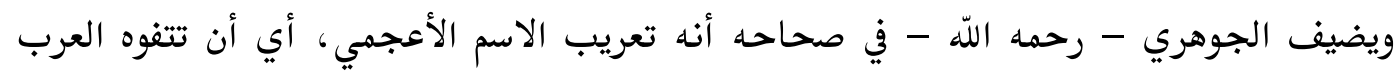

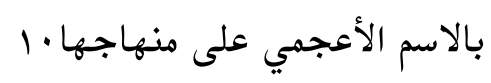

$$
\begin{aligned}
& \text { V ابن منظور، لسان العرب، (بيروت: دار احياء التراث العربية، ^•؛ () ص هبr } \\
& \text { 1 المصدر نقسه ، ص •10 }
\end{aligned}
$$

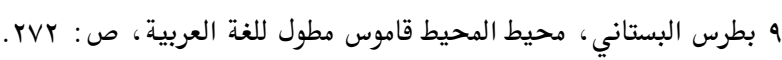

$$
\begin{aligned}
& \text {. } 1 \text { إبراهيم الحمد، فقه اللغة قضاياه، ص : lov . }
\end{aligned}
$$

'A Jamiy, Jurnal Bahasa dan Sastra Arab Volume 06, No. 2, September 2017 
ويقول الجوهري عنه : " والتعريب هو نقل اللفظة من الأعجمية إلى العربية، وحتى يطلق على اللفظ المعرب معربا، لا بد أن يتوفر فيه شرطان وهما أولا : أن يكون اللفظ المنقول من الأعجمية إلى العربية قد جرى عليه تغيير في البناء وثانيا : أن يكون اللفظ قد نقل إلى العربية في عصر الاستشهاد، ذلك بأن يرد في القرآن الكريم أو الحديث النبوي الشريف أو كلام العرب الذي يحتج بكلامهمم|

ومما جاء في كتب المحدثين عنه وهو : " اللفظ الأجنبي الذي غيره العرب بالنقص أو

الزيادة أو القلب "، أي أن تتكلم العرب بالكلمة الأعجمية على نهجها وطريقتها، وأن تخضع ما هو أعجمي لضوابط وقواعد وخصوصيات اللغة العربية"rا وهناك من أطلق على المعرب الدخيل، كونه لفظ أجنبي دخل العربية، وخضع لتغيرات وفق ضوابط العربية، في حين أنه لا يمكن إطلاق لفظ الدخيل على المعرب كون الدخيل غير معرب واستعمل كما نقل من لغته الأصل، ويشير كثير من الباحثين إلى أن العرب عاشوا أواسط القرن الرابع للهجري عقب الأمصار، أي الذين عاشوا عصر الاحتجاج، أما من عاصروا الفترة التي بعد ذلك، وهم من العرب غير الخلص، فهم من يطلق عليهم المولدون . ويقول الجوالقي عن الدخيل : " ويبدو الفرق بين المعرب والدخيل هو أن الدخيل أعم من المعرب، فيطلق على كل ما دخل في اللغة العربية من اللغات الأعجمية سواء أكان ذلك في عصر الاستشهاد أم بعده وسواء خضع عند التعريب للأبنية العربية أم لم يخضع.با فالمعرب ما كان من الألفاظ دخيلا أجنبيا استعمله فصحاء العربية وأما المولد فهو ما استعمله المولدون من ألفاظ أعجمية لم يعربوهاء ا. وأما عن اللفظ المولد فذكره الزمخشري على أنه : " كلام مولد أي ليس من أصل لغتهم"، وعرفه السيوطي : " هو ما أحدثه المولدون الذين لا يحتج بألفاظهم "، وأما بالنسبة للمعجم الوسيط 11 أبو منصور الجوالقي، المعرب من الكلام الأعجمي على حروف المعجم، (هدار القلم، دمشق، طا، .199)، ص: Tr إميل يعقوب، فقه اللغة العربية وخصائصها، (بيروت: دار الثقافة الإسلامية، 19AY) ص: Y

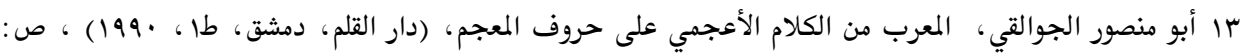


والأساسي فعرفاه على أنه اللفظ الذي استعمله الناس بعد عصر الرواية، وعرفه المجمع اللغوي العربي على أنه : " اللفظ الذي استعمله المولدون على غير استعمال العرب"، فيظهر في خلال التعريفات المختلفة للفظ المولد في الاصطلاح أنه لم يثبت بدقة من حيث المفهوم كون البعض حدده بفترة ما بعد عصور الاحتياج والآخر على أنه ما ابتكر من قبل جماعة أو تم اختراعه 10 ويرجع الباحثون سبب دخول اللفظ الأعجمي اللغة العربية وتعريبه في القديم، إلى ما أتيح للشعوب الناطقة بالعربية قبل الإسلام وبعده من فرص للاحتكاك المادي والثقافي والسياسي

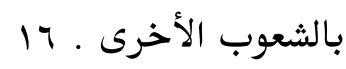

ومن أشهر ما عرب في عصور الاحتجاج من السريانية والعبرية : اليم / الطور / الربانيون / طه /إبراهيم / إسماعيل / شرحبيل / وعادياء ومن الحبشية ( المشكاة، الكفل، الهرج، المنبر، الأرائك، ومن اليونانية عن طريق السريانية بعض مصطلحات الطب والمنطق والفلسفة والمعادن كالقبرس والبطريق والقنطرة والفردوس والقراميد والقسطاس والسجذججل ومن الفارسية : الكوز، المسك، العنبر، الكافور، الصندل. IV

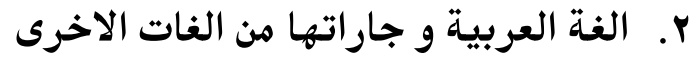

لا شك أن العربية مشحونة بألفاظ أعجمية اقترضتها عن لغات أخرى عبر معيشتها وسياستها ولا سيما اللغات والمجتعات التي هي أكثر تمضرا وقوة تفرض تأثيرها على نحو من أنحاء على المجتمعات الأقل تحضرا وقوة, هذا ما حدث بين الأمم العربية والبابليين, والفرس والمصريين, واليونان, والروم, كما قال السيوطي في كتابه المزهر: " فإن لخما وجزاما كانوا مجاورين لأهل مصر والقبط, وقضاعة و غسان وإياد كانوا مختلطين مع الأراميين والعبرانيين, وثعلب واليمن كانوا بالجزيرة مجاورين لليونان, وبكر للفرس والهند, وأهل اليمن كانوا مختلطين مع الهنود والحبشة, وسكان صحاري الجزيرة والعراق كانوا مخالطين للفرس والنبطيين, وغيرهم لغيرهمیا.

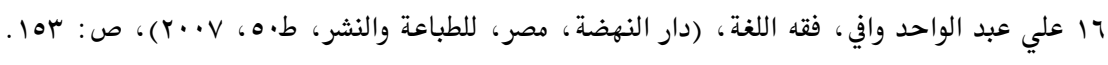

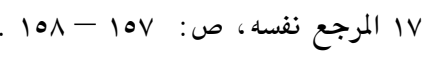

^االمزهر في اللغة للا مام جلال الدين السيوطي ص شرح وتحقيق محمد أحمد جاد المولى وعلى محمد البجاوي ومحمد

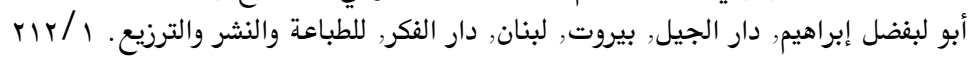

\section{'A Jamiy, Jurnal Bahasa dan Sastra Arab}


ويؤخذ من هذا القول بأن العربية أثرت وتأثرت بالفارسية والعربية القديمة واليونانية والرومية والهندية وغيرها من اللغات, ونعرض في السطور الأتية موجز الاحتكا بين هذه اللغات :

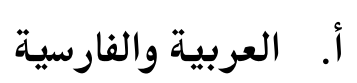

اللغة الفارسية هي إحدى اللغات الهند وأروبية أو فصيلة من فصاإلها التي تنتمى كلها إلى أصل واحد وهو الفارسية القديمة, أو الأرية, وتمتد هذه اللغات "الهند أروبية " جغرافيا من الهند إلى أمريكا ويتكلم بها أناس في استراليا وقسم من أريقيا, وتعد من أهم المجموعات اللغوية في العالم, وتفرعت منها لغات كثيرة, مثل " الختنية, الهند وإيرانية, والأرمنية والبالتية, والسلافية, والألبانية والبندوقية والإيليرية, واليونانية, والتركية, الفريجية والكلتية, واللاتينية, والتخارية والكوشية, أو "الكوجية" والجرمانية" 19.

ويعتقد بأن أهل هذه اللغة كانوا يعيشون في الفلوت الواقغة بين روسيا وأسيا الوسطى وحول بحر قروين ثم انطلقوا من هنا إلى الجهات المختلفة في أنحاء العالم.r. وكانت علاقة الغرب بالفرس قبل الإسلام أقوى وأظهر من علاقتهم بجير انهم الأخرين, وهذه العلاقة المتميزة كانت أساس ما حدث بين الشعبين-العربي والفارسي-من صلة لغوية قوية قبل الإسلام وبعده. وهذه العلاقة أدت إلى أن تترك كل من اللغتين في الأخرى أثرا لغويا كبيرا, متمثلا في المفردات والأساليب والأخيلة والتراكيب, ولكن أثر العربية في الفارسية كان أوسع نطاقا من أثر الفارسية في العربية ويظهر هذا الأثر بشكل واضع من ناحية المفردات منذ أن كانت العراق "أو البحيرة" حلقة الاتصال بين الشعبين الكبيرين حين كان للغرس حصون في الكوفة والذجف على ضفة الفرات الغربية في حدود البادية بينها وبين العراق, وهذه الحصون والقصوركانت تستخدم لحماية حدود الفرس من غارات البدو, وكان سكانها من العرب وغير العرب, ولهم ملوك

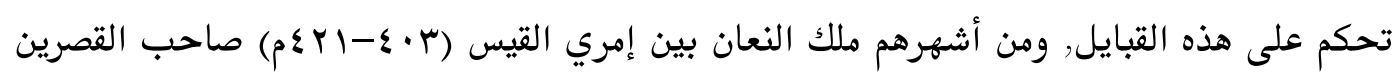

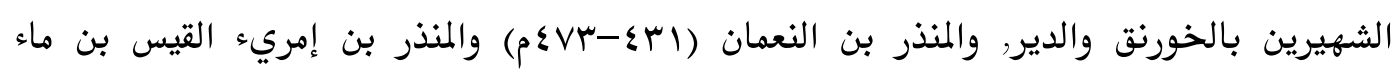

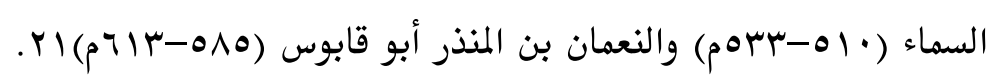

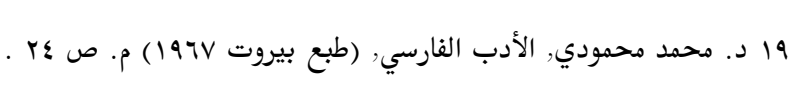

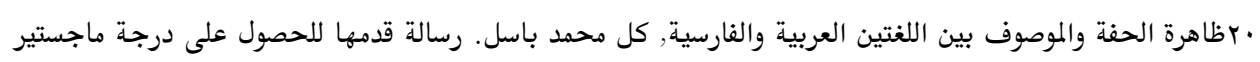

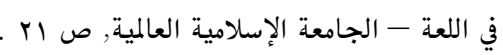

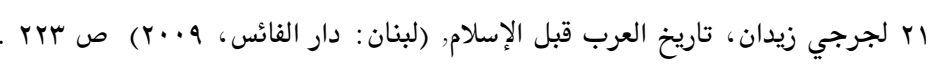

\section{A Jamiy, Jurnal Bahasa dan Sastra Arab}

Volume 06, No. 2, September 2017 
هذه هي إشارة عابرة إلى المعالم والطرق الرإيسية التي كانت تربط بين اللغتين الربية والفارسية على مر العصور, واقترضت العربية من الغارسية كلمات كثيرة وأذكر بعضا منها للمثال ولا للحصر:

-أذركون : أذريون : نوع زهره صفراء "معناها الأصلي: بلون النار".

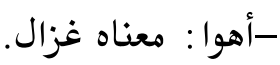
- |ابريسم: إبريشم: الحرير. - إبريق : "كلمة مركبة" من أصل "أب + ريز" من جذر "ريحتن", إناء يصب به الماء

$$
\begin{aligned}
& \text {-بابوج: من أصل فارسي "يايوش" معناه"الحذاءr } \\
& \text { - أسفنذ أو أسينذ: خردل أبيض. } \\
& \text {-أنبار: مخزن, من "انباشتن" "تخزين الشيء؟r. } \\
& \text { ب. العربية واللغات الأخرى: }
\end{aligned}
$$

ولا شك في أن الشعوب المجاورة لايمكن أن تعيش بمعزل بعضها عن بعض, واللغة-

أكونها ظاهرة اجتماعية إنما تنحو وترعرع في أحضان مجتمع ما- أيضا كهذه الشعوب لا يمكن أن تتطور بمعزل عن التأثيرات الخارجية عليها واحتكاكها مع غيرها كاحتكاك الشعوب والحضارات, والحضارات الأكثر تحضرا وقوة تفرض تأثيرها على الحضارات الأقل تحضرا وقوة, وعلاوة على علاقة الجوار هناك علاقة أخرى لاحتكاك هذه اللغات وهي علاقة العاإلة بين اللغتين, كتأثير اللغات السامية بعضها ببعض ولاسيما الأرامية والحبشية مع العربية. وكان العرب يحتك بجيرانهم الأاميين في شمال جزيرة العرب عن طريق التجارة والهجرة والرحلات وامتزاج بعض القباإل الغربية بالارامية, وكان الاراميون يتمركزون في سهول سوريا, وبوادي الشام ويسيطرون على محطات القوافل الواقعة على خطوط التجارة البرية القديمة, ودور اللغة الأرامية في مذطقة الشرق الأوسط أكثر أهمية من دور الأراميين, فقد انتشرت الأرامية انتشارا واسعا وأصبحت لغة التجارة والدبلوماسية, بل إنها حلت محل العبرية, وبعد فتع الأسكندر الأكبر

$$
\begin{aligned}
& \text { rrيايوش: أيضا كلمة مركبة من "يا أي رجل" و"يوش, أي: لبس أو علاف" }
\end{aligned}
$$

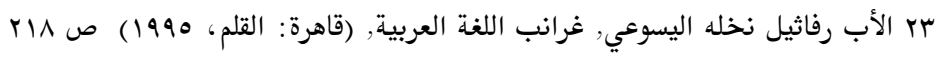

\section{'A Jamiy, Jurnal Bahasa dan Sastra Arab}


احتفظت بمكانتها إلى جانب الينانية و هي لهجات كثيرة ساإدة في كل بلاد فلسطين وسوريا, وبين النهرين وفي بعض مناطق العراق.

وكان تجار مكة يتعاملون مع الأراميين في دمشق, وكانت قوافل تجارتهم تجتاز جزيرة العرب وتنتقل بين أسواقها, وكانت الأرامية بالإضافة إلى أهميتها في عالم لبسياسة والمال, لغة الدين اليهودي الذي أمن به بعض لبعرب كما كانت أيضا من أهم لغات النصرانية التي دان بها

$$
\text { كثير من عرب الحيرة وغسان؟r. }
$$

وأهم الكلمات الحبشيةالتي دخلت اللغة العربية تعود إلى أشياء دنية, مثل "حواريون, ونافق, أو منافقون, وفطر, ومنبر, ومحراب, ومصحف, وأإك "جمع أريكة" والجبت, والشيطان, وبرهان مع بعض الألفاظ النادرة التي جات أو وردت في القران الكريم, وفي الحديث الشريف, تشهد بالمناسبات الصحيحة بين المسلمين وبلاد الحبش قبل الهجرة. وهكذا كانت تتم الاقتراضات بين العربية وأختها السامية وهي الحبشية. -الحواريون: حبشية, جمع حواري أو الرسول من أي: سار ومشىهب. - المنافقون :حبشية, ونافق مأخوذ من نفك إلى شك وداهن,والمنافق تشتق من نافق أى : تابع لطاإقة مخالفة للعامة. -منبر: أصلها منبر أى: المقعد. -ومحراب: أصلها أى : المعبد, فإبدلت الميم الثانية باء؟r. - البرهان : حبشية. ومن جانب اخر احتك العرب بأقوام وشعوب غير الأمم السامية ومنها اليونان. العربية واليونانية:

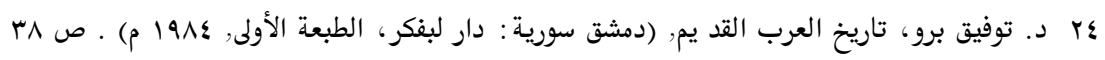

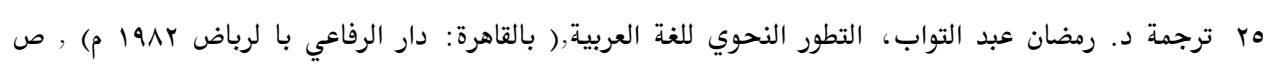

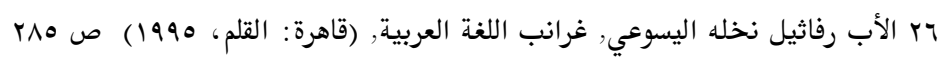

\section{'A Jamiy, Jurnal Bahasa dan Sastra Arab} Volume 06, No. 2, September 2017 
ويعود تاريخ هذا الاحتكاك الذي تم بين العرب واليونان إلى فتح الإسكندر سورية وفلسطين ومصر وما بين النهرين حوالي عام •مق.م. والمفردات اليونانية التي اسعارها العرب في هذا الدور تكاد لا تذكر, ويبتدئ ثانيهل وهو الدور الذي يعنينا هنا-باحتلال الرومان "الروم" مصر سنة "•r ق.م" ويورية وفلسطين سنة §ج ق.م ولقسم من العراق, وينتهي هذا الدور با حتلال العرب لهذه الأقطار و غيرها من البلاد التي كانت خاضعة للدولة البزنطية في إفريقيا وأسيا. وفي هذا الدور ظهرت إمارة عربية في داخل سورية وفلسطين هي إمارة بني غسان, وكانت ذات استقلال نوعي, وسلطة فعلية على عرب سورية وفلسطين وبعض أطراف الحجاز, وذات علاقات سياسية وعمرانية متينة مع الدولة البرنطية وعمالها في القطرين المذكورين, ثم دخول سكان هذه الإمارة في الذصرانية, وتردد أمراإها وأساقفتها وتجارها على عاصمة الملكة, وقد أدى هذا- ولا شك- إلى اختلاط كبير بين الأمتين, وكان من نتاإج هذا الاختلاط بين إمارة غسان والدولة البزنطية أن أصبحت هذه الإمارة العربية في القرنين الأخيرين "قبل انتشار الإسلام فيها" أرقى الإمارة العربية وأغناها يؤمونها من جميع أطراف الجزيرة, لمدح أمراإها, واللتجارة أو للسكنى, ويأخذون عنها ما كانوا يرونه هناك من أسباب الحضارة والترف, وما كانوا يسمعون من الأسماء العربية. وساعد الروم هذه الإمارة لدفع العغارات البدوية عن حدوها وللاستعانة بهم في حروبهم مع دولة فارس وبناء على هذه الاحتكاكات المتبادلة بين الشعبين- العربي واليوناني- تم التبادل لأخذ الكلمات بين العربية واليونانية وأخذت العربية من اليونانية كلمات كثيرة وجل هذه الكلمات دخلت إلى العربية عن طريق ارامية وسبب ذلك أن العرب قبل أن يحتكوا بل لأمة اليونانية وادابها كانوا قد احتكوا بالأرامين- إذن- انتقل إلى العربية من اليونانية عن طريق مباشر وغير مباشر أى عن طريق الأرامية وخاصة السريانية منها, مثل أساء ألات الرصد والجراحة وبعض إل مصطلحات الطب والفلسفة والمنطق والعلوم الطبية والطبيعية, وأساء بعض المعادن والوظااف والمنشئات المعمارية وأدوات البناء والموازين والأمتعة "كالقبرسن أي أجود أنواع النحاس" والبطريق واليقطون أى البيت الشترى, والقنطرة, والفردوس أي البستان, والقرامية "الاجر" والقسطاس "الميزان" والقنطار والبطاقة والسجذجل "المرأة" والاسطراب, والنقرس, والقولنج "مرضان" والترياق,

$$
\text { دواء السموم rV. }
$$

rrr rانظر: دراسات في القاهوس ص •rr

\section{'A Jamiy, Jurnal Bahasa dan Sastra Arab}

Volume 06, No. 2, September 2017 
هذه الكلمات السالف ذكرها دخلت العربية عن طريق السريانية من الأصل اليوناني, وأيضا أخذت العرب عن اليونان مئات من المفردات ولهذا يرجحون أن أكثر المفردات اليونانية التي دخلت العربية موجودة في الأرامية كذلك, ومثال الكلمات اليونانية كالأتي: إبليس : بحذف المقطعين الأولين وزيادة الألف على أول الكلمة لابتدائها بساكن وتحويل إلى.

$$
\begin{aligned}
& \text { أزميل: أسورة } \\
& \text { إقليد : إكسير } \\
& \text { درهم: دمقس } \\
& \text { دكان : سندس^ץ }
\end{aligned}
$$

طلسم: كتابة يستعملها الساحر زاعما أنه يدفع بها الأذى. قرطاس : ورق يكتب عليه.

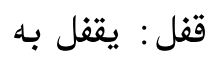
كورة: ناحية من البلد.

هذه الكلمات كلها يونانية, كما ورد في معجم جفري, وكذلك قال : بر جشستراسر في كتابه "التطور الذحوي99.

ومن جانب أخر بدأ الاحتكاك بين العرب والرومان وذلك منذ احتلال الرومان سورية وفلسطين في عام في عام "ه •ا ق.م" وقسما ما بين النهرين وحين حاولوا أن يردوا بعض قبائل عرب الشمال إلى داخل البلاد, ليأمنوا شرهم ويعاقبوهم على غزواتهم للمقاطعات العربية الرومانية, وقد ظلت هذه العلاقات وثيقة العرى حتى أواخر الفتح الإسلامي لتلك الأقطار سنة ه آم تقريبا, مع أن بعض قياصرة القسطنطنية الذين كانت تخضع لسيطرتهم تلك الأقطار يتكلمون اليونانية, وإن اللغة الاتينية كانت- أحيانا- لفة الحكم والإدارة, ومن ثم كان العرب في تلك الأقطار مضطرين إلى اقتباس بعض مفرداتها التي كانت تدعوهم الحاجة إليها.

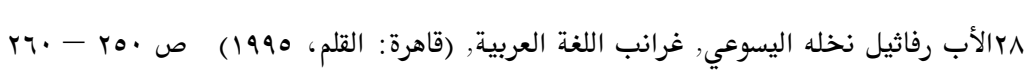

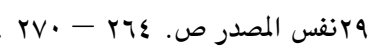

\section{'A Jamiy, Jurnal Bahasa dan Sastra Arab}


ودخلت كلمات كثيرة لاتينية في العربية إما مباشرة إما عن طريق الفارسية واليونانية والسريانية أو العبرانية, وذلك في المجالين: المجال التجاري والمجال الإداري لاسيما ألقاب الولاة, وتأثرت العربية باللاتينية في هذين المجالين فقطر مثال ذلك كالأتي:

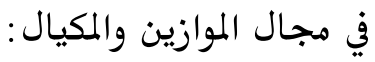

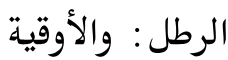
والقيراط: والقنطار وهو مائه رطل, ثم صار يدل على الكثرة كما في القران الكريم "زين للناس حب الشهوات من النساء والبنين والقناطير المقنطرة من الذهب والفضة"•ــ. المد : من أو القسط وهو في الأصل نصف صاع. والقسطاس والقبان أو الكيال أو القفال كلها بمعنى الميزان ومن أسماء النقود مثل : الدينار. وهي يونانية اللأصل, والدرهم: هي يونانية الأصل دخلت العربية عن طريق الرومان, الفلس: جمع فلوس, وهي قطعة صغيرة من النقود النحاسية أو القريرية وثمة كلمات أخرى دخلت العربية عن طريق التجارة مع الولايات البزنطية أو الرومانية مثل : الصك. القرطاس: من الورق كان يتخذ من بردي وعلق على الصحيفة. وكذلك أخذت العربية من الرمانية كلمات في الإدارة والجيش, والحرب مثل: القيصر: وقد وردت في كثير من أشعار العرب قبل الإسلام وبعده. الأمبراطور: من بمعن غلب وقهر, القائد والسيد والحاكم. البطريق : والجمع منه البطارقة : الشريف الحر, أحد الأعيان. وهكذا ترس: الأطربون: الشيغ : أي رئيس القرية. منجنيق : زرد حلق المغفر الدرع. السجل : علامة, شعار طابع كتابة.

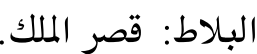
القنطرة: جمعه قناطر وكذلك دخلت كلمات أخرى في مجال أخر مثل: ••بالقرآن الكريم, ) سورة ال عمران, الاية: عا (جاكرت: غما رسالة فريس، ه191 ) ص •؛

\section{'A Jamiy, Jurnal Bahasa dan Sastra Arab}




$$
\text { الفرن جمعه أفران, المخبر, الكور: المحجرة : الرأس من كل شيء. }
$$

هذه هي إشارات ضئيلة في عرض اللغة العربية وجاراتها من اللغات السامية والغير

سامية, وذلك تمهيدا ومذطلقأ منه إلى الهدف الأصلي وهي عرض فكرة التعريب في اللغة العربية.

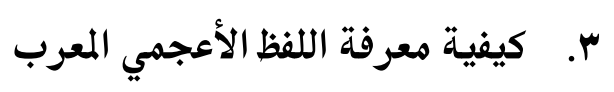

يمكن معرفة اللفظ الأعجمي المعرب في لغتنا من علامات تقع على مستوى اللفظة والإشارة بالنقل عن العلماء، الذين يشيرون في كثير من الحالات إلى أن اللفظة ليست عربية، وكأن تخالف أيضا اللفظة الوزن العربي، كأن يخرج الاسم بالأعجمية في وزنه عن وزن الاسم بالعربية، كابرسيم أو نجد اللفظة تبدأ بالنون ثم يليها حرف الراء كنرس ونرجه أو كأن يكون آخر اللفظة زايا بعد دال كمهندز، أو أن تجتمع كل من الصاد والجيم أو الجيم والقاف أو الياء والتاء والسين أو الجيم والطاء وذلك في مثل الألفاظ التالية : الصولجان والمنجنيق والبستان والطاجن، وهناك بعض الألفاظ الأخرى، التي ذكرها الباحثون في معرفة الأعجمي المعرب، يراعون فيها الميزان الصرفي والتقارب الصوتي كقولهم عن الصحراء :

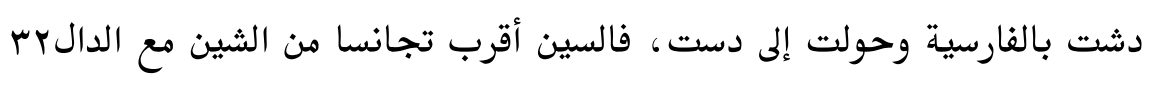
هناك ألفاظ أعجمية كثيرة كانت العرب في حاجة إلى استعمالها لتحقق بها أغراضها، فاضطرها ذلك لتعريبها ومنها : ألفاظ الأواني كالإبريق والطشت والخوان والقصعة والجرة وألفاظ الملابس كالفنك والدلق والسندس والديباج، ومن الجواهر : الفيروزج والبلور ومن الطيب المستعمل : الكافور، العنبر، القرنفل، المسك، ..

وأما السبب الثاني، فهو أن العرب تستعمل أحيانا اللغز والإغراب في كلامها، مما اضطرها لاستعمال بعض الألفاظ، مما هو أعجمي وله مرادفاته في العربية، كالدشت وهي الصحراء والقيروان والجماعة وأصلها كروان، أضف إلى ذلك إعجابهم بخفة بعض الألفاظ الأعجمية التي سارعوا في تعريبها، حتى أن هذا النوع الخفيف من الألفاظ كان يحل أحيانا مكان الألفاظ

$$
\begin{aligned}
& \text { ابالمصدر السابق،غرانب اللغة ص rVV - • r } \\
& \text { rr رضان عبد التواب، فصول في فقه اللغة، (قاهرة: مكتبة الخانج، 19V9) ص : بآr }
\end{aligned}
$$

\section{'A Jamiy, Jurnal Bahasa dan Sastra Arab \\ Volume 06, No. 2, September 2017}


العربية الأصيلة المرادفة لها، ومن ذلك التوت الذي كان يسمى الفرصاد والياسمين المسمى بالعربية السمسق .

$$
\text { ع . تحليل الكلمات المعربة في القرآن الكريم بنظر الى تاريخها }
$$

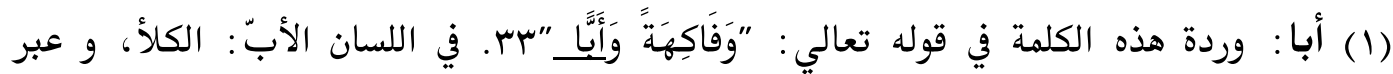
بعضهم عنه بأنه المرعى. وقال الزجاج: الأبّ جميع الكلأ الذي تعتلفه الماشية. قال أبو حنيفة : شمي اللّ تعالى المرعى كله أبّا. قال الفراء: الابّ يأكله الأنعام. وقال المجاهد: الفواكهة ما أكله الناس، والابّ ما أكاه الأنعام، فالابّ من المرعى للدواب كالفاكهة للإنسان و في المعجم الوسيط: الأبّ: العشب رطبه ويابشه. وتقول: فلان راع له الحب، وطاع لهالابّ: زكازرعه والتسع مرعاه.

$$
\text { و في لغة في (الابّ) عـ }
$$

والابّ: كلمة معربة وقد إختلف علماء اللغات حول أصلها: فير السيوطىيهـ: أنها: بربرية وتعني الحشيش. ووافق في هاذا الزركشي وشيخ حمزة فتح الله. ويري رفائل نخلة اليسوعي: انّ الابّ تعني الثمرة وهي من أبا: ئ́ كلمة مقتبشة من

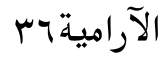
(Y) إبراهيم : يقول الرازي: إبراهيم إسم أعجمي، و فيه لغات : إبراهام و إبراهم بحذف الياء... والبراهمة: قوم لا يجوزون علي الله تعالى بعثة الرسول.

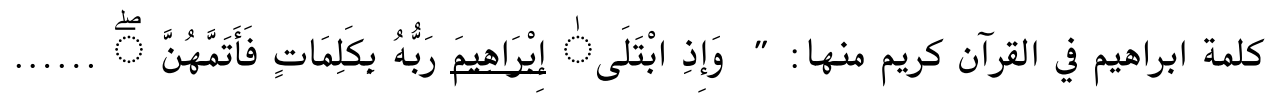
"VIV" "ابراهيم" اسم قديم، ليس بعربي. وهذا "ابراهيم" معربة عن العبرية و أصله (أبراهام) وهو لغة في (أبرام) و معناه: الأب، رفيع أو عال.

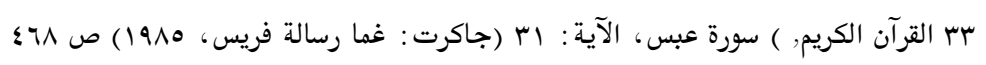

عَباإبرايم أنس و عبد الحليم وعطبه الصوالحي ومحمد خلف الله أحمد، المعجم الوسيط، ( دار المعارف: الطبعة الثانية

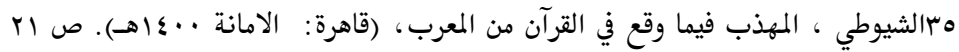

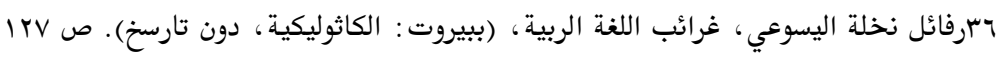

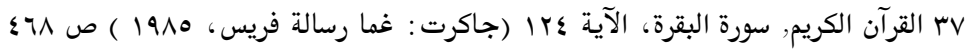

\section{'A Jamiy, Jurnal Bahasa dan Sastra Arab}


والهمزة في الأصل مفتوحة إلا أنها كسرت عند التعريب، وقلبت الألف ياء احتذاء

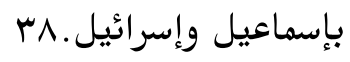

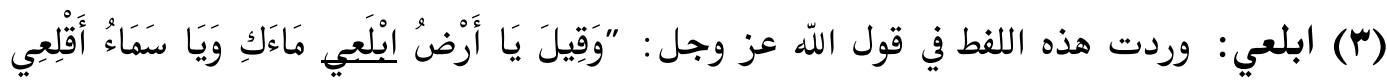
. ... الحبشية، لأن اللغة الآرمية كانت اهم الغات النصرانية، ولقد دخلت النصرانية الحبشة ف القرن

و مما يؤكد آرامية هذه الكلمة، وجود المادة (بلع) في الآرامية. و روي ليسلاو: أن هذالجذر (بلع) جذر سامية مشترق موجود في العربية، والعبرية، والآرامية، و السريانية، والمندعية، والحبشية، و من هنا نري أن الكلمة (أبلعي) صيغة عربية أصلية من (بلع) (ع) إبليس: يقول ابن منظور: و أبلس من رحمة الله أي يئس وندم، ومنه سمى إبليس وكان إسمه عزازيل ... وإبليس لعنه الله : مشتق منه لأنه أبلس من رحمة الله أي أويس. وقال أبو إسحاق : لم يصرف لأنه أعجمي معرفة. يقول الجواليقي: "إبليس" ليس بعربي، وإن وافق أبلس الرجل، إذا انقطعت حجته ، إذا لو كان منه لصرف. ألا تري أنك سميت رجلا: بـ إحريط او إجفيل، لثرفته في المعرفة. و منهم من يقول: هو عربي، ويجعل إثتقاقه من "أبيلس-يبلس" أي يئس. فكأنه أبلس من رحمة الله. ويريى براجستراسر أن "إبليس" من الكلمات اليونانية التي دخبت العربية في الزمان المتأخر. ويرافقه الدكتور السبحا حيث يقول عن "إبلس" هو يناني و أصله (دِيَابُلُس) و معناه: النمام والعدو و الشيطان. و يعتقد ان الدال في اول الكلمة جذف في سريانية ظناً أنها أداة الإضافة. (0) أباريق: وردت هذه اللفظة في قوله تعالى :"بأَكْوَابِ وَأَبَاريقَ وَكَأْس مِنْ مَعِين" ·عيقول إبن منظور: والاباريق : إناء، وجمعه أباريق، فارسي معرب. قال بعضهم، الإبريق السيف هاهناً، سمي به لبريق. وقال غيره: الإبريق هاهناً قوس فيه تلاميع، وجارية إبريق : براقة الجسم.

$$
\begin{aligned}
& \text { ^r عبد الرحمن عبد السبحان، المعرب والدخيل في اللغة العربية، (لبياء: دار المعارف، دون تاريخ) ، صـ }
\end{aligned}
$$

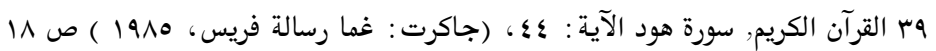

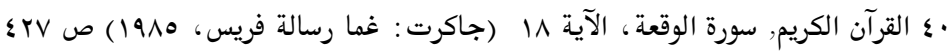

\section{'A Jamiy, Jurnal Bahasa dan Sastra Arab Volume 06, No. 2, September 2017}


يقول الجواليقي: الإبؤيق: فارسي معرب ترجمته من الفارسية أحد شيئين: اما أن يكون طريق الماء او صب الماء على هينة.

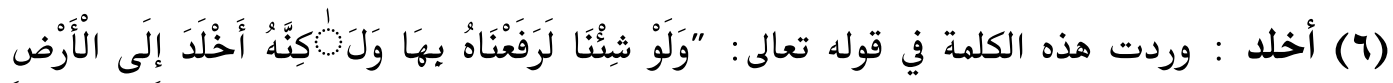

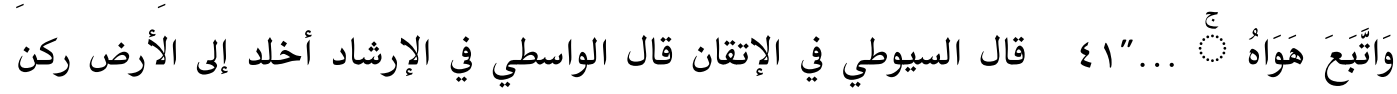
بالعبرية.اهـ.

أقول: هذا القول لا يقوله إلا جاهل باللغات السامية فإن أخلد وخلد موجودتان في اللغتين كلتيهما ومتفقتان في معانيهما في الجملة فمن قال اتهما عبريتان وليستا عربيتين لقد قفاما لا علم له به ومن قال العكس فهو مثله، غير أن (أخلد) في العبرانية بالحاء المهملة، وكذلك (خلد) وقد تقدم أن الخاء المعجمة لا توجد بالأصالة في العبرانية و إنما توجد بالعرض في حرف الكاف إذا جاءت بعد حركة، ولم نر أحدا علماء اللغة العربية أشار إلى أن(أخلد)عبرانية كما ادعى هذا المدعي .قال

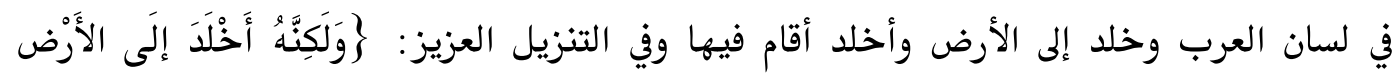
وَاتَّبَعَ هَوَاهُ أن ركن إليها وسكن وأخلد إلى الأرض وإلى فلان أي ركن إليه ومال إليه ورضي به، ويقال خلد إلى الأرض بغير ألف وهى قليلة.اهـ.

وقال البيضاوي في تفسيره وَلَكِنَّهُ أَخْلَدَ إلَىى الأَرْضَ مال إلى الدنيا أو إلى السفالة وَاتَّبَحَ هَوَاهُ في إيثار الدنيا واسترضاء قومه وأعرض عن مقتضى الآيات. (1) الأرائك: قال السيوطى في الإتقان: "حكى ابن الجوزي في فنون الأفنان أنها السرر بالحبشية" اهـ .قال الراغب: " الأريكة حجلة على سرير جمعها (أرائك وتسميتها لذلك إما لكونها في الأرض إن له متخذة من أراك وهو شجرة أو لكونها مكانا للإقامة من قولهم أرك بالمكان أروكا وأصل الأروك الإقامة على رعى الأراك ثم تجوز به في غيره من الإقامات" اهـ. و قال في لسان العرب والأريكة سرير في حجلة والجمع أريك وأرائك، وفي التنزيل "عَلَى الأَرَائكِكِ مُنَّكِثِونَ" قال المفسرون : الأرائك السرر في الحجال، وقال الزجاج: الأرائك الفرش في الحجال، وقيل: هى الأسرة وهى في الحقيقة الفرش كانت في الحجال أو في غير الحجال، وقيل الأريكة سرير منجد مزين في قبة أو بيت فإذا لم يكن فيه سرير فهو حجلة. وفي الحديث "ألا هل عسى رجل يبلغه الحديث عنى وهو متكئ

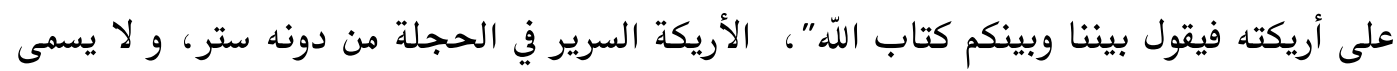

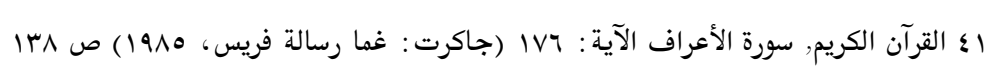

\section{'A Jamiy, Jurnal Bahasa dan Sastra Arab}


منفردا أريكة ."اهـ. قال في اللسان: "والحجلة مثل القبة وحجلة العروس معروفة وهى بيت يزين بالثياب و الأسرة والستور"، فقد رأيت أن الأرائك كلمة عربية خالصة، وبطل ما ادعاه السيوطى

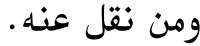

هذه ويري العنيسى أن أريكة : يونانى ari-koite معناه : فراش وثير ومرقد جيدץ؟

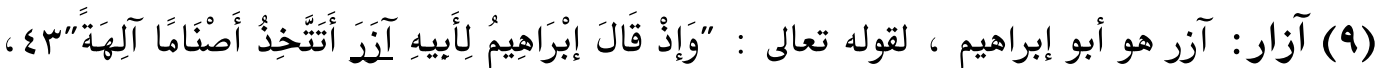
وهذا نص قطعى صريح لا يحتاج إلى اجتهاد ، ورجح ذلك الإمام ابن جرير وابن كثير " انتهى.عبد العزيز بن باز - عبد الرزاق عغيفى - عبد الله بن غديان - عبد الله بن قعود. وبهذا يتبين أن " آزر " هو اسم والد إبراهيم الحقيقى كما هو ظاهر القرآن والسنة ، وهو القول الراجح إن شاء الله تعالى ، وذلك لا يعنى نفى أن يكون " تارح " أيضا اسم علم له ، سواء في لغة أخرى ، أو عند قوم آخرين ، خاصة وأن بعض الدارسين في اللسانيات يقررون أن اسم " آزر " هو نفسه اسم " تارح " وإنما طرأ عليه شىء من التغيير مع مرور الزمان وتغير اللهجات يقول الدكتور عبد الرحيم الهندي : وهناك احتمال آخر ، وهو أن لفظ آزر هو تارح ، طرأ عليه شىء من التغيير ، قد يبدو هذا غريبا ، ولكن الحقائق تؤيد هذا الاحتمال. إن اسمه المذكور في ، وفي ترجمة التوراة اليونانية المعروفة بالترجمة السبعينية كتب اسمه

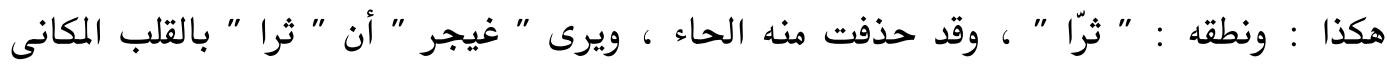
أصبح " آثر "، ثم " آزر. " ومثل هذا التغيير جائز الوقوع ، ومثال آخر لذلك " عيسى "، وأصله بالعبرية " يشوع " فقد انتقلت فيه العين من آخر الكلمة إلى أولها ، وأصبحت الواو ياء " انتهى لهى من تحقيق " المعرَّب من الكلام الأعجمى على حروف المعجم " للجواليقى ومن مراجع التفسير : " زاد المسير " ، " الجامع لأحكام القرآن " ، " تفسير القرآن العظيم " ، " التحرير والتنوير " ولا يفوتنا التنبيه هنا إلى أن الاختلاف في اسم أبي إبراهيم عليه السلام ليس من مسائل العقيدة التي يبحث فيها عن قول أهل السنة والجماعة ، بل هي مسألة علمية اجتهادية للاجتهاد فيها حظ واسع من النظر ، وقد قال بكلا القولين من كبار المفسرين من الصحابة والتابعين ومن

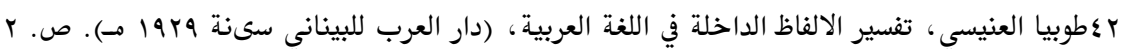

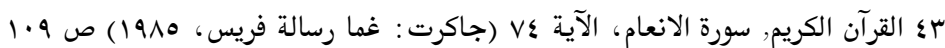

\section{'A Jamiy, Jurnal Bahasa dan Sastra Arab}


(•) أشباط: قال السيوطي في الإتقان: "حكى أبو الليث في تفسيره أنها بلغتهم كالقبائل بلغة الغرب" اهـ. وفي هذا الكلام شيء ساقط لأن الضمير في لغتهم لم يذكروا ما يعود عليه وهذا الساقط يحتمل أن يكون يدل على بني إسرائيل وكلام جفري يؤيد هذا الاحتمال وهذا نص ترجمته

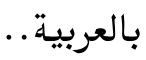

اضطر أبو الليث أن يعترف أنه أي السبط لفظ عبراني مستعار، قاله السيوطي في الإتقان.

وقد أطال جفري البحث في هذا اللفظ وادعى أنه لم يستعمل في كلام العرب قبل استعماله في القرآن وربما يكون أول من استعمله محمد.

ونحن نقول لجفري وأمثاله من الذين أعمى التعصب بصائرهم وأفقدهم صوابهمم: إن الله

الذي أنزل التوراة و الإنجيل اللذين تؤمن بهما أنت هو الذي أنزل القرآن على عبده ورسوله محمد

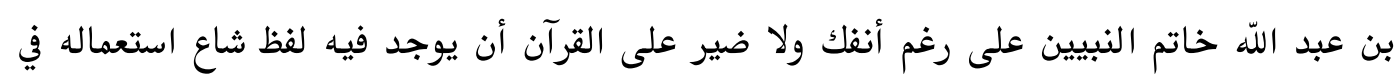
العبرانية لأن هاتين اللغتين نشأتا من أصل واحد وإذا جاز أن يكون في القرآن ألفاظ هي في الأصل فارسية مع أن لغة الفرس بعيدة من لغة العرب فما المانع أن توجد فيه ألفاظ عبرانية أو سريانية؟ هن وإذا اعتبرنا السبط اسما لقبيلة من قبائل بتي إسرائيل فالتعبير به طبيعي وهو أولى من التعبير عنه بالقبيلة لأنه صار شبيها بالأعلام التي يجب ذكرها بلفظها. قال في لسان العرب: "والسبط من اليهود كالقبيلة من العرب وهم الذين يرجعون إلى أب واحد، سمي سبطا ليفرق بين ولد إسماعيل وولد إسحاق وجمعه أسباط. وقوله عز وجل:

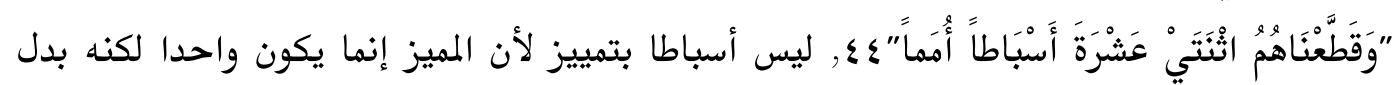

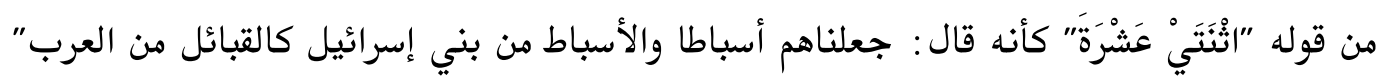
واصله بالعبرانية (شبط) على وزن ابل ومعناه القضيب والعصا والقبيلة. (11) إسحاق: يقول الرازي: سحث الشيء فانسحق : أيّ سهكه، وبابه قطع، والسحق أيضا: الثوب البالى. وإسحق إسم رجل. فإن أرادت به الاسم الاعجمي لم تصرفه في المعرفة الأنه غير عن وجحته فوقع في كلام العرب غير معروف المذهب، ةإن أرادت المصدر من قولك أسحقه السفر إسحاقا: أي أبعده، صرفته ، لأنه لم يتغير.ه هـ

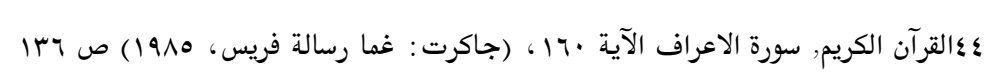

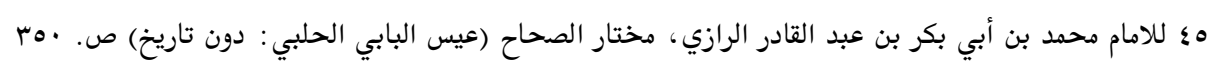

\section{A Jamiy,Jurnal Bahasa dan Sastra Arab \\ Volume 06, No. 2, September 2017}


ويقول الجواليقي: "إسحاق" أعجمي، وإن وفق لفظ العربي. يقال: أسحقه الله يسحقهُ

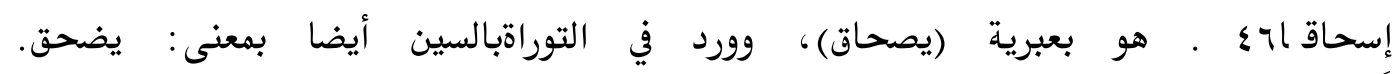

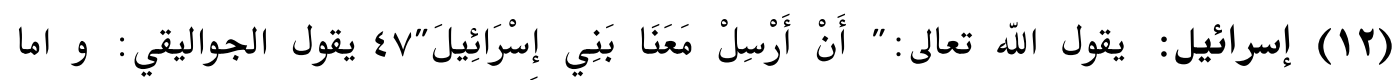

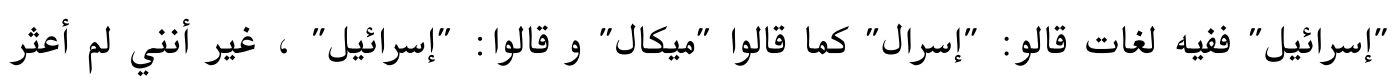

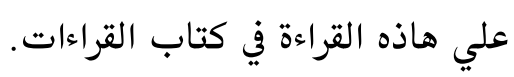

أيا ماكان الامر، فكلمة "إسرائيل" معربة عن العبرية، و أصلها في اللسان العبي

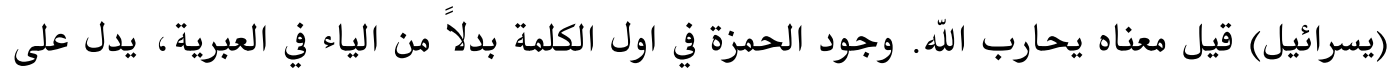
كونه دخلا في العربية عن الطريق السريانية فهو فيها : "إسرائيل".

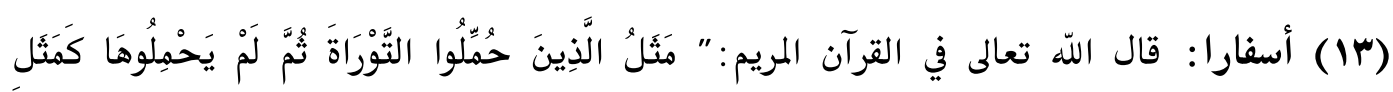

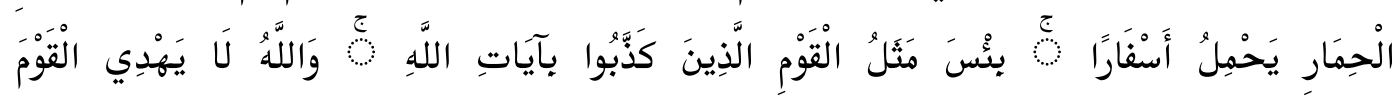
الظَاَّلمِينَ

قال السيوطي في الإتقان "قال الواسطي في الإرشاد هي الكتب بالسريانية وأخرج ابن أبي حاتم عن الضحاك قال : هي الكتب بالنبطية" اهـ.

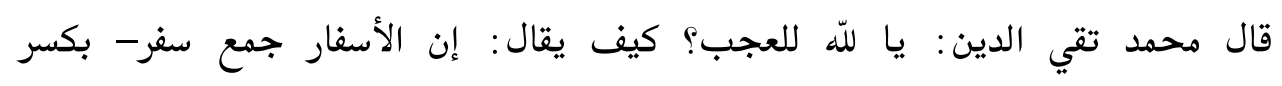

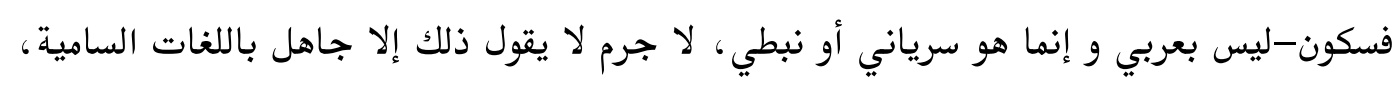

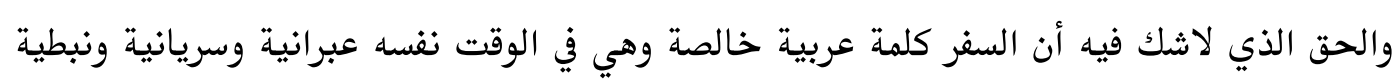
فهي من الألفاظ المشتركة بين اللغات السامية ليست واحدة منها أولى بها من غيرها.

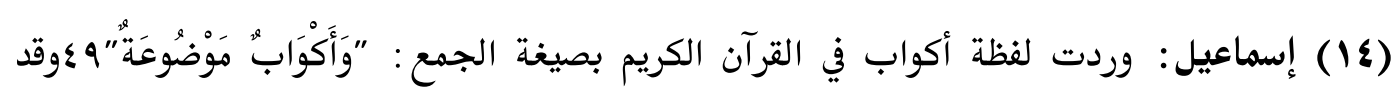

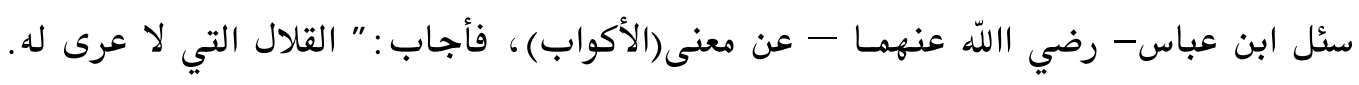

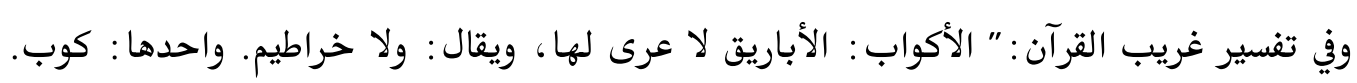

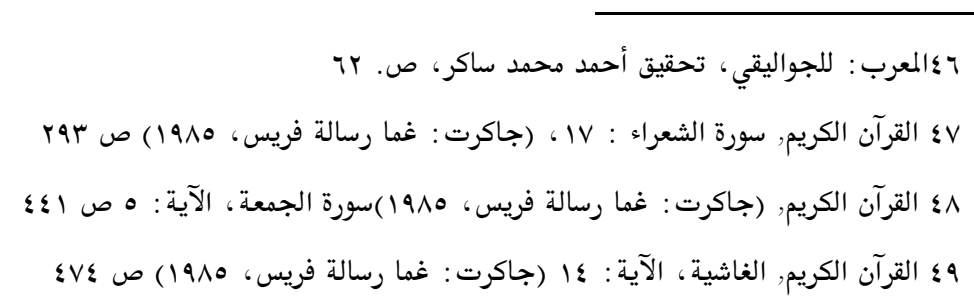

\section{'A Jamiy, Jurnal Bahasa dan Sastra Arab} Volume 06, No. 2, September 2017 
وينقل السيوطي عن ابن جرير: " أن الأكواب جرار ليس لها عرى وهي بالنبطية كوبا.

ويشير رفائل اليشوعي: إلي أن ألكوب كلمة مكتبسة من اللاتينية، و معناعا: إبريق صغير بلا

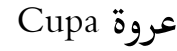

(10) إلاًّ: يقول ابن مذظور: والال: الحلف والعهد. وبه فسر أبو عبيدة قوله تعالى : " كَيْفَ وَإنْ

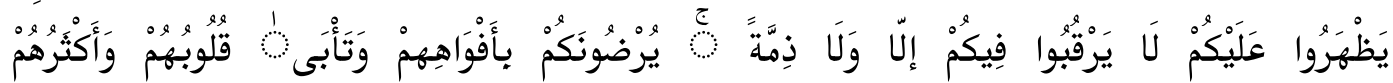
فَاسِقونَ"،ه ـ. و الال: القرابة. و في التهذيب: جاء في التفسير أن يعقوب بن إسحاق على نبينا وعليهما الصلاة والسلام كان شديدا فجاءه ملك فقال: صلرعني، فصارعه فصرعه يعقوب: فقال له الملك إسرإلّ، و إل اسم من أسماء الله عز وجل بلغتهم. ويقول السيوطي نقلاً عن مجاهد في التفسيرأن: "الال" اللّه تعالى. وعن ابن جني في المحتسب: قالوا الال بالنبطية : اسم الله تعالى. هذانري أن كلمة "الال" عبرية، دخل إلي اللغة العربة عن طريق البطية إحدى اللهجات الارامية. ففي المعجم العربي الانجلجي للعهد القديم: "الال" مأخوذة من ellehim و بمعنى

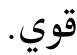

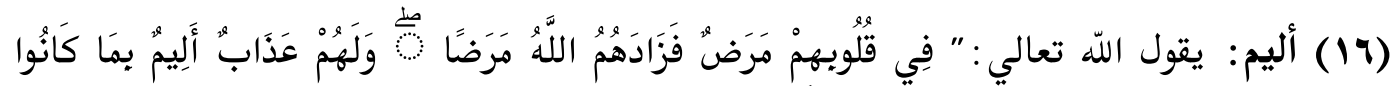
يَكْذِبُونَ" في اللسان: الألم: الوجع، والجمع آلام. وقد أليم الرجل يألم ألماً، فهو أليم. والأليم: المؤلم الموجوع مثل السميع بمعنى المسمع. وذكلر الذركشي : أن "الاليم” المؤلـــم بالعبرانية وقال السيوطي: حكي ابن الجوزي: انه الموجوع بلزنجية، وقال الشيدلة في البران أنه

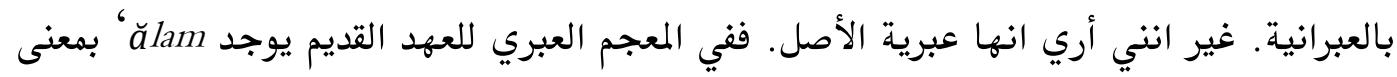
آلم، كما يوجد جميع اشتقاقاتها.

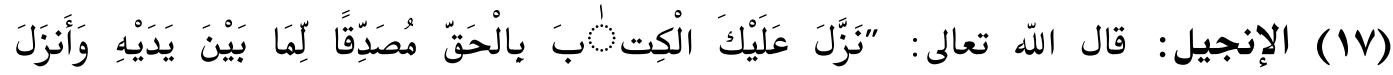

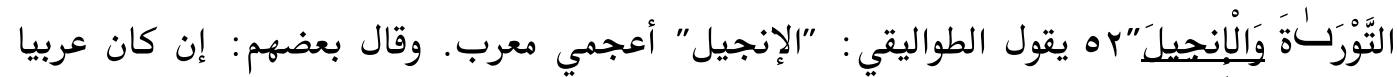

$$
\begin{aligned}
& \text { •ه القرآن الكريم, سورة التوبة، الآية : ^ (جاكرت: غما رسالة فريس، 1919) ص } 101
\end{aligned}
$$

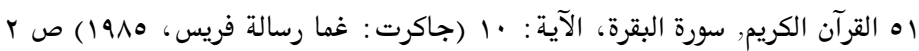

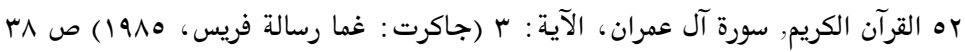

\section{'A Jamiy, Jurnal Bahasa dan Sastra Arab}


فشتقاقه من "النَّجل" وهو ظهور الماء علي وجه الأرض واتساه. وفي اللسان: "واليحكم أهل

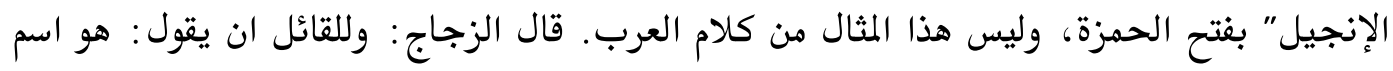

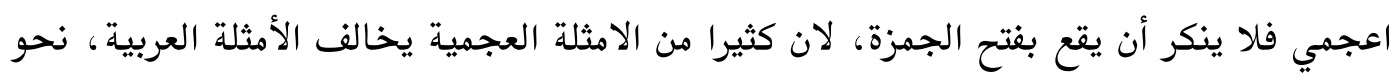

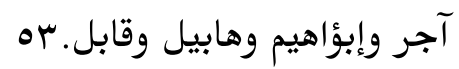

وعلي أية حال، فكلمة "الإنجيل" معربة عن اليونانية و أصلها في هذا اللسان (eungelion)

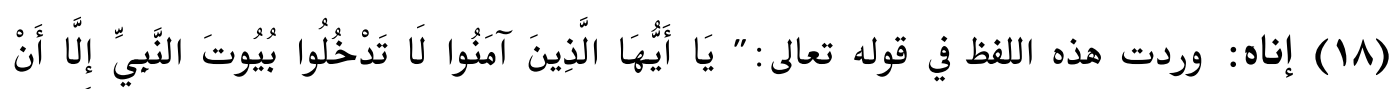

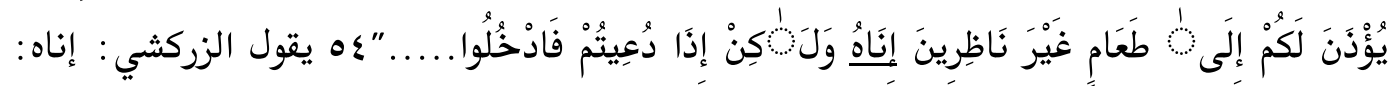

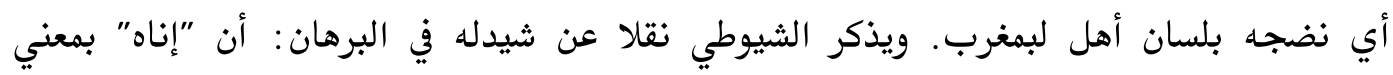

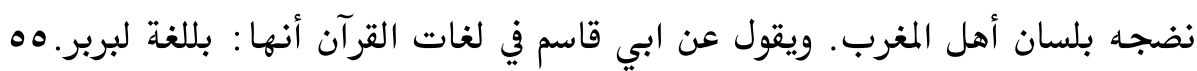
ومن المقرور أن اللغة البربرية هي لغة أهل المغرب. و في معجم غريب القرآن: إناه:

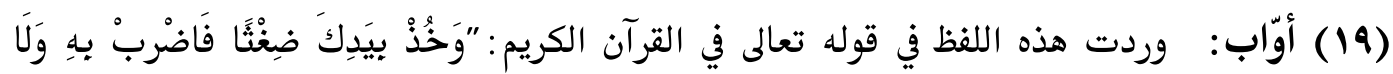

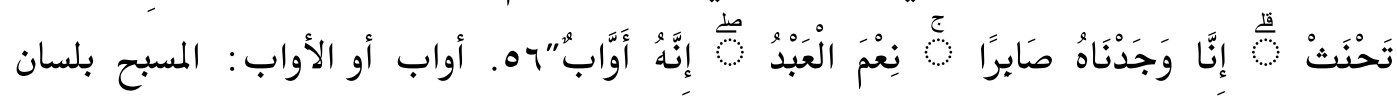

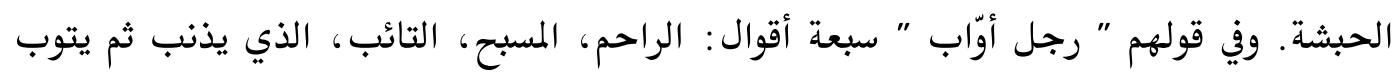

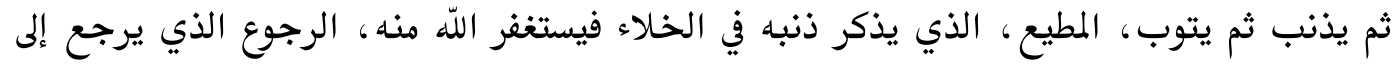

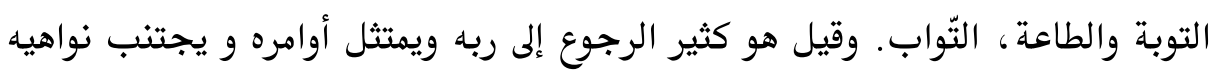
أوب الأوب: ضرب من الرجوع، وذلك أن الأوب لا يقال إلا في الحيوان الذي له إرادة، والرجوع يقال فيه وفي غيره، يقال : آب أوبا وإيابا ومآبا. يقول السوطي: نغلا عن ابي حاتم عن عمرو بن شرحبيل قال: "الأوّاب": المسبه بلسان

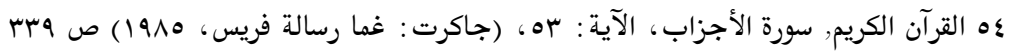

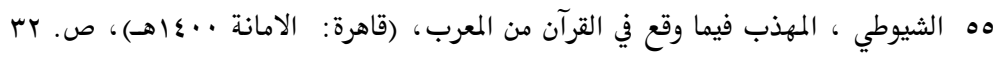

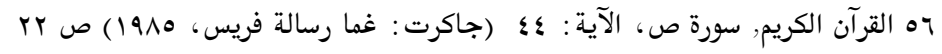

\section{'A Jamiy, Jurnal Bahasa dan Sastra Arab \\ Volume 06, No. 2, September 2017}




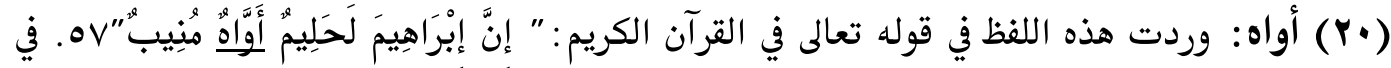
اللسان: رجل أوّاه: كثيرالحزن: وقيل: هو دعاء إلى الخير، وقيل: الفقيه، وقيل: المؤمن، بلغة الحبشة، وقيل، الرحيم الرقيق. في تفسير غريب القرآن: الاوّاه: المتأوه حزناً و خوفاً.

يقول السيوطي: قال أبن حاتم عن مجاهد وعكرمة قالا: "الأوّاه" الموقن بلسان الحبشة. وقال ابن حرير عن ابى ميسرة قال: "الأوّاه" الرحيم بالحبشة. ونري أن هذه الكلمة حبشية، حيث لم يرد لها أي ذكر في المعجم العربي الإنجلزي للعهد الديم.

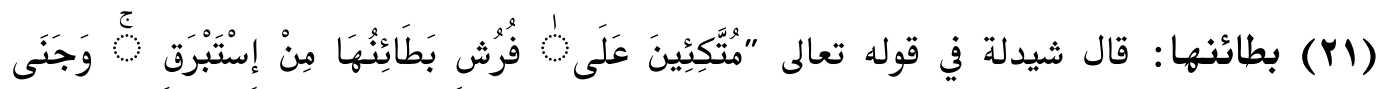
الْجَنََّيْن دَان"هـ. أي ظواهرها بالقبطية ، حكاه الزركشي.

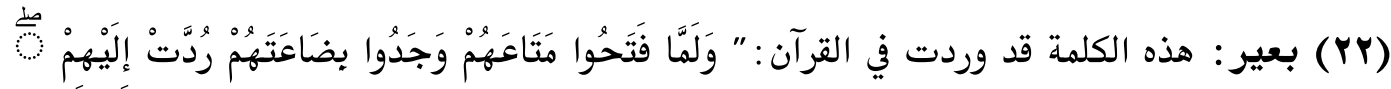

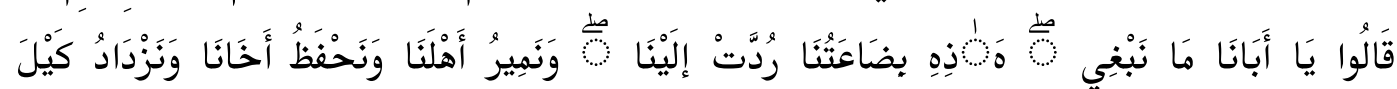

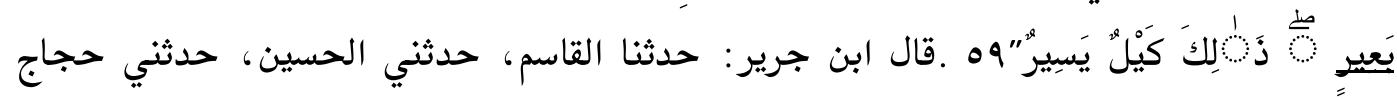
عن ابن جريج عن مجاهد في قوله تعالى (حمل بعير) قال : حمار. قال وهي لغة. قال ابن خالويه في كتاب (ليس) هذا حرف نادر ذكر مقاتل عن الزبور: البعير كل ما يحمل بالعبرانية.

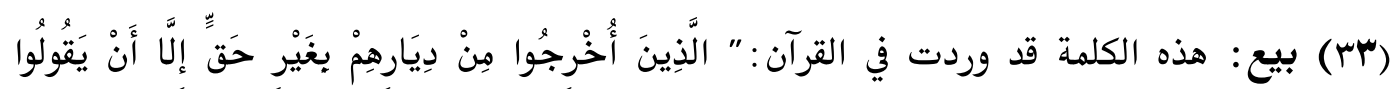

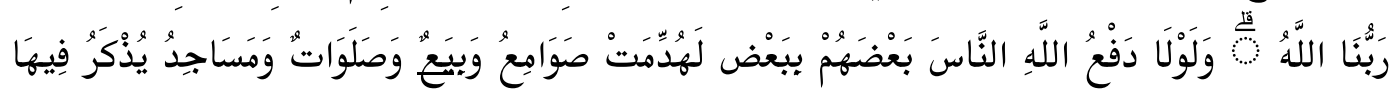

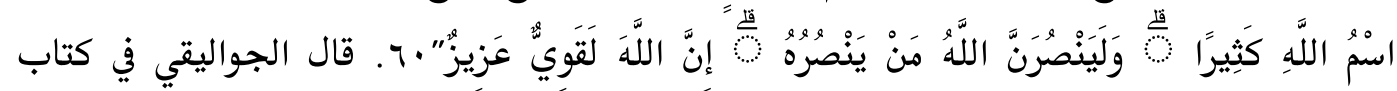
المعرب : (البيعة والكنيسة جعلهما بعض العلماء فارسيين معربين).

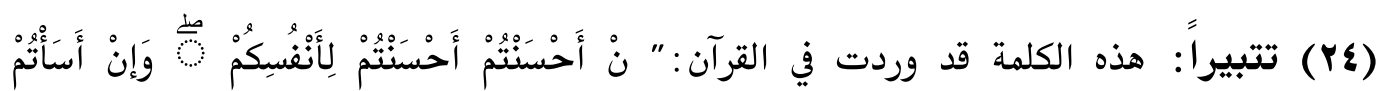

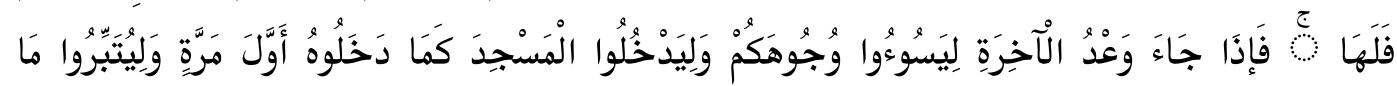
عَلَوَا تَتْيِيًَا" الج. قال ابن أبي حاتم : ذكر عن القواري حدثنا يحيى بن يمان عن أشعث عن جعفر عن سعيد بن جبير في قوله تعالى : "وَلَيَتَبروا ما عَلوا تَتبيراً" قال تبره بالنبطية.

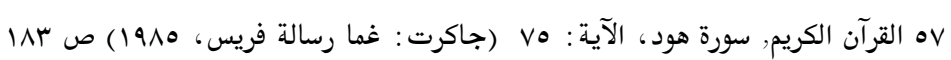

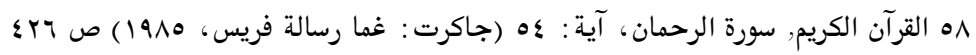

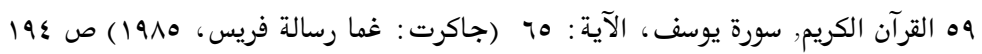

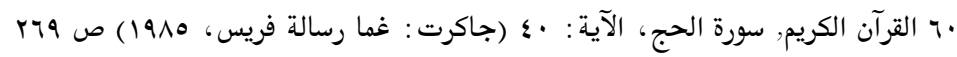

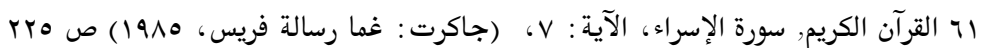

\section{'A Jamiy, Jurnal Bahasa dan Sastra Arab}


وقال ابن جرير حدثنا أبو كريب حدثنا ابن يمان به.

يشير رفائيل النخلة اليسوعي إلي أن: تتبر بمعني كسره، و هي كلمة آرامية و معلوم أن النبتية لهجة من لهجات الآرامية الغريبة.

(Y0) تحت: قال أبو القاسم في (لغات القرأن) في قوله تعالى :" فَنَادَاهَا مِنْ تَحْتِهًَا أَلَّا تَحْزَنِي قَدْ

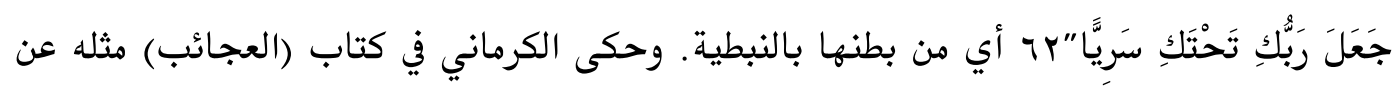
مؤرخ السدوسي رحمه اللهّ تعالى.

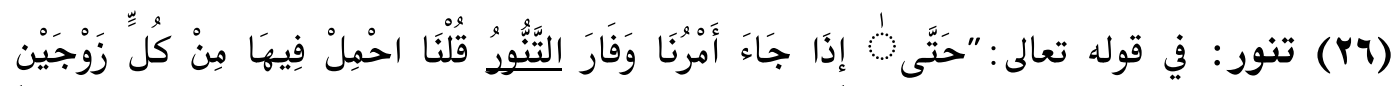

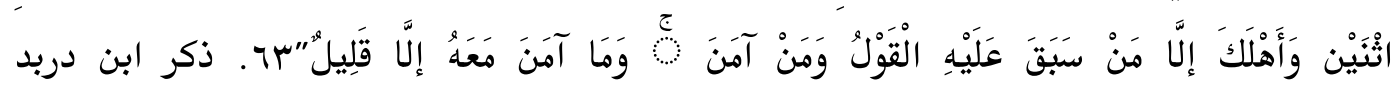
والجوالبقي والثعالبي أنه فارسي معرب. (YV) التوراة: يقول الزمخشري: "والتوراة و الإنجيل" اسمان أعجميان، و تكلف اشتقاقهما من الورى و النجل، و زنهما بتفعلت و إفعيل غنما يصح بعد كونهما عربيين وذكر طوبيا العنيسي أن "توراة" كلمة عبرية، مأخذة من " تورة" ومعناها عندهم عادة فتعليم فشريعة. و طلق علي أسفار موسى الخمسة، وهو مشتق من "بره" أي ألقي ووضع. ويشير

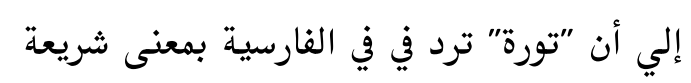

ونرى أن كلمة "التوراة" عبرية أصيلة، معخوذة من tōrā العبرية، إلا انها دخلت العربية عن طريق اللغة الآرمية، وهي فيها أي الآرامية ōrayţa ودليل علي هذا : أن رسمها في القرآن بلياء يوافق لفظها الآرمية

(YA)

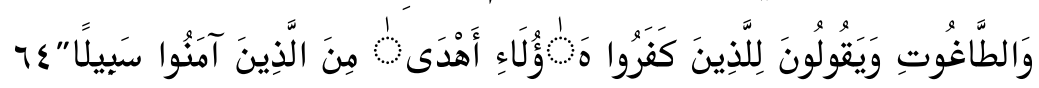
قال ابن أبي حاتم : ذكر عن نعيم بن حماد البصري، حدثنا عبد الحميد بن عبد الرحمن

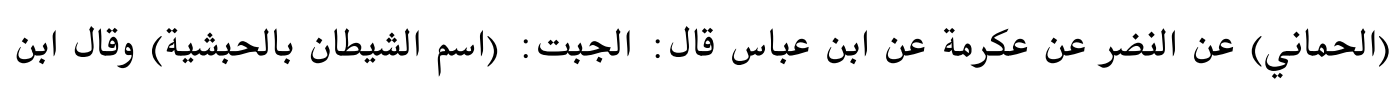

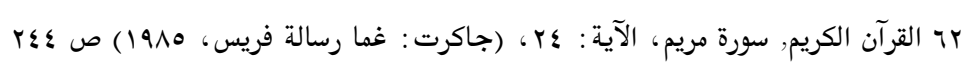

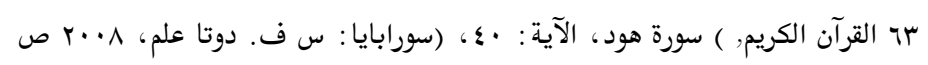

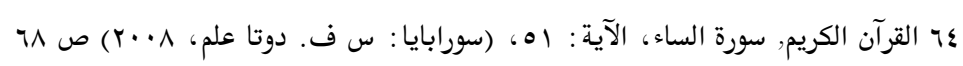

\section{'A Jamiy, Jurnal Bahasa dan Sastra Arab}

Volume 06, No. 2, September 2017 
جرير: حدثنا ابن بشار، حدثنا محمد بن جعفر حدثنا شعبة عن أبي بشر عن سعيد بن جبير قال : الجبت الساحر بلسان الحبشة والطاغوت : الكاهن. وفي العجائب للكرماني أن أصله جبس.

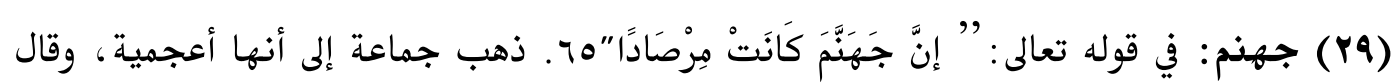
بعضهم فارسية معربة. وقال آخرون: هي تعريب كهنام بالعبرانية.

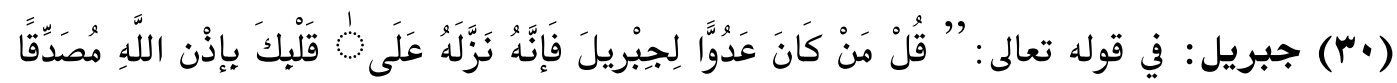

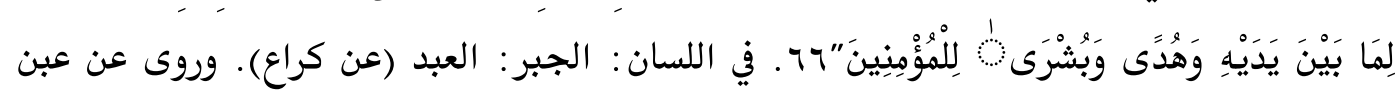
عباس في جبريل وميكائيل كقولك عبد الله و عبد الرحمن. يقول الاصمعي : ومعني إيل هو البوبية فأصيف جبر و ميكا إليه. قال أبو عبيد: فكأن إيل: رجل إيل. يقول الدكتور السبحان : جبريل بالعبرية و معناه: رجل اللهوVT.

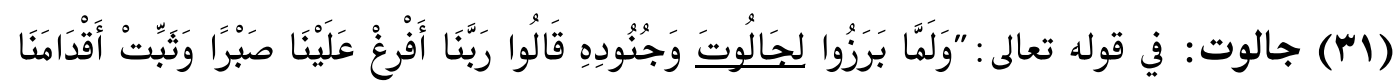

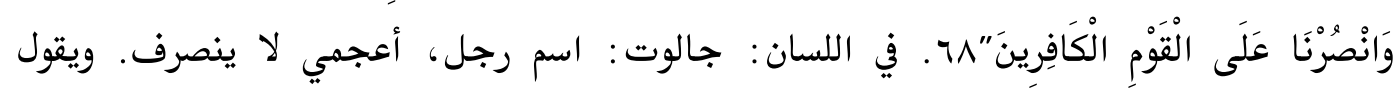
الجولقي: "جالوت" : أعجمي. وقد جاء في القرآن. و نري أن هذا اللفظ أعجمي، دخل العربية من العبرية.

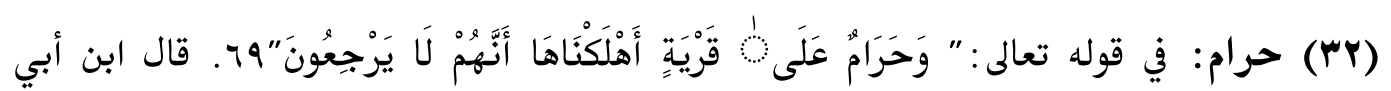
حاتم ذكر الحسن بن محمد الصباح حدثنا حجاج عن ابن جريج، أخبرني عطاء أن عكرمة قال:

$$
\text { (وحرم: وجب بالحبشية). }
$$

ويقول السوطي: "حرام" قال ابن ابي حاتم أن عكرمة قال: "حرام": وجب بالحبشة •V.

نقول: نري أن حرم بمعنى وجب مأخوذة من الحبشة، أما حرم من الحرام وهو بمعني: نقيض الحلال، فهو لفظ سامي مشترق : فهو في الجبشة : حرم: arama' بمعن منع.

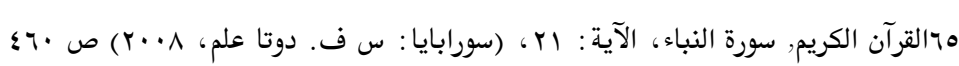

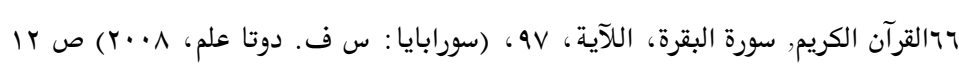

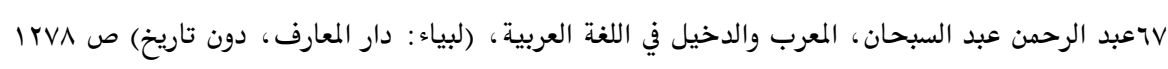

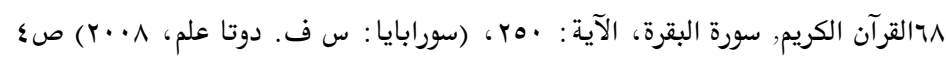

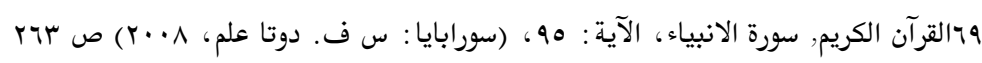

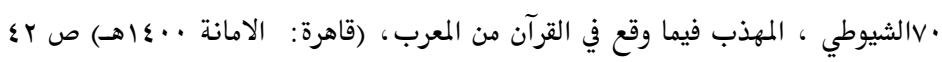

\section{'A Jamiy, Jurnal Bahasa dan Sastra Arab}

Volume 06, No. 2, September 2017 


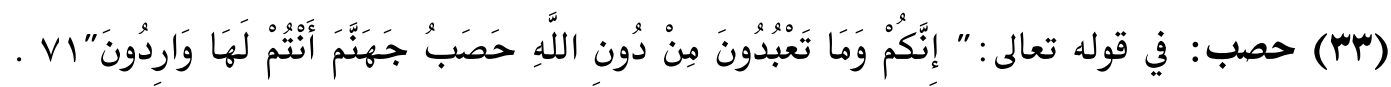

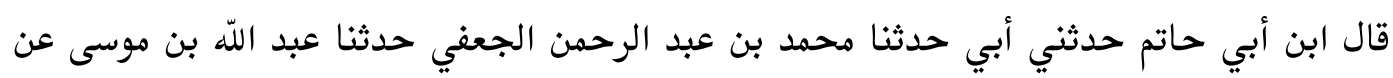

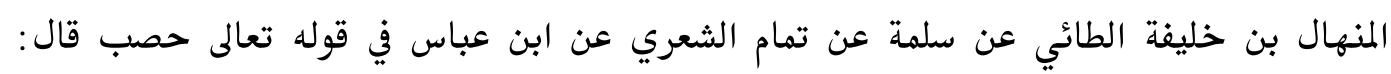
(حطب جهنم بالزنجية). (حسن

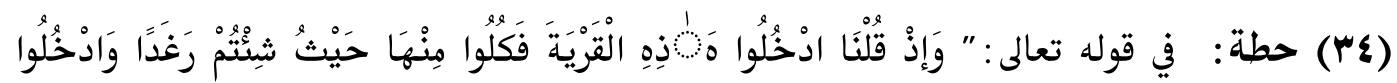

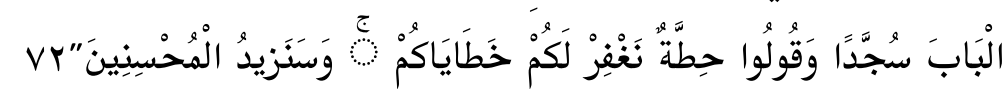

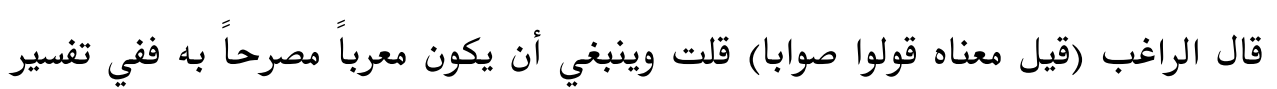

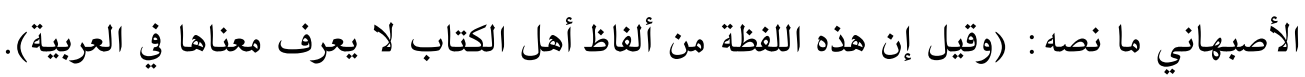

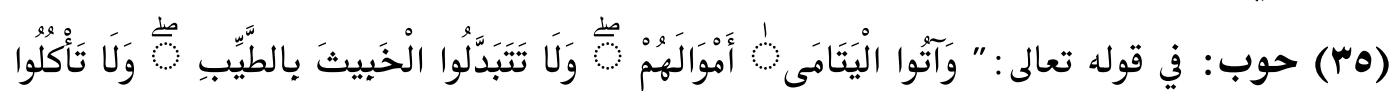

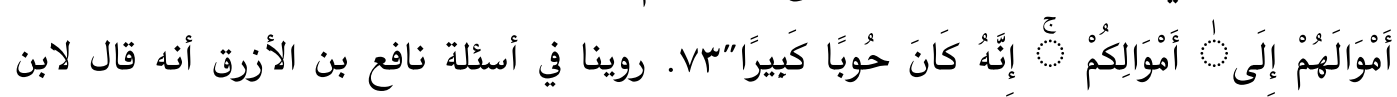

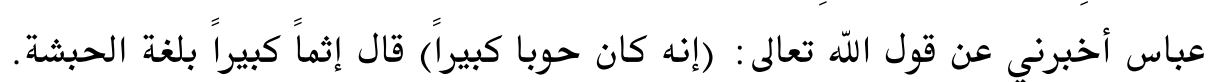

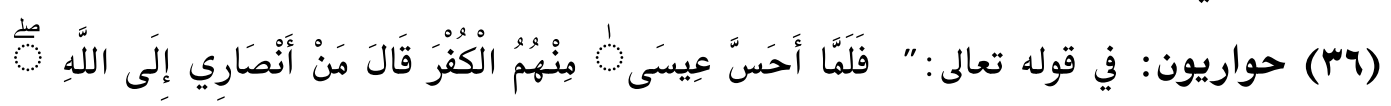

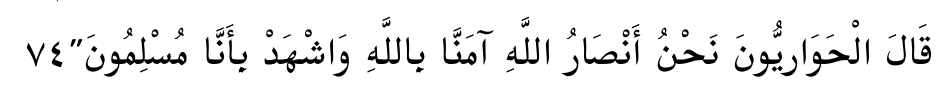
قال ابن حاتم حدثنا أبو سعيد الأشج، حدثنا الوليد بن القاسم عن (جويبر) عن الضحاك

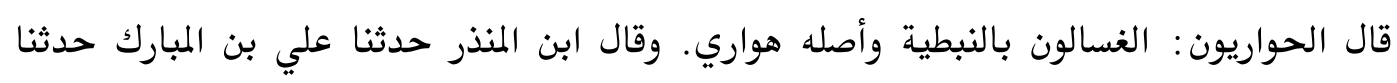

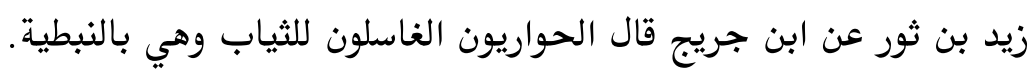

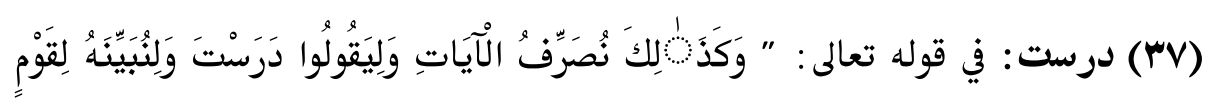
يَعْلَمَونَ"Vه. عده الحافظ بن حجر في نظمه ، وذكر بعضهم أن الدراسة القراءة بالعبرانية.

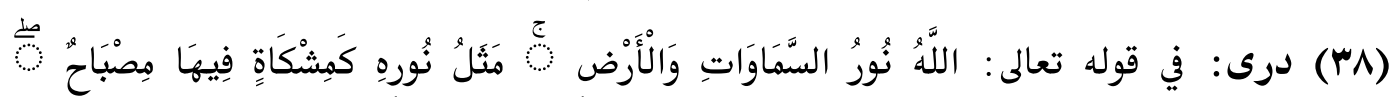

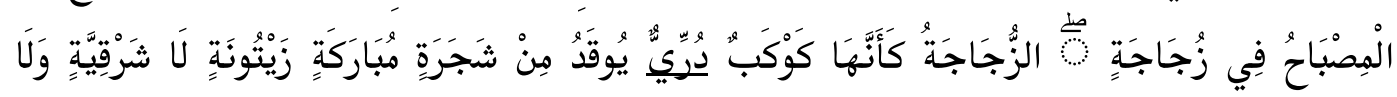

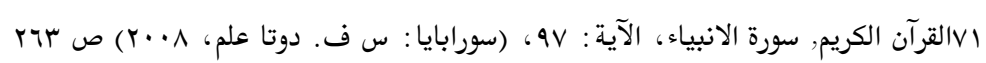

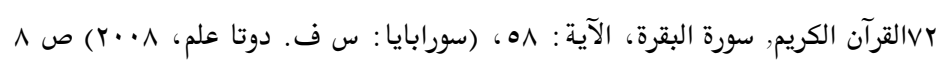

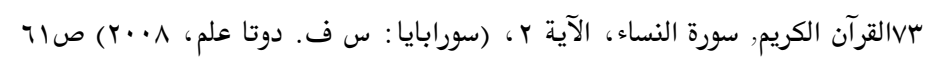

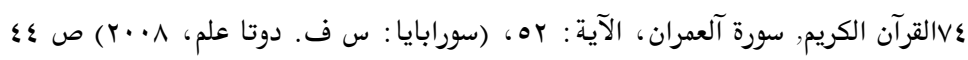

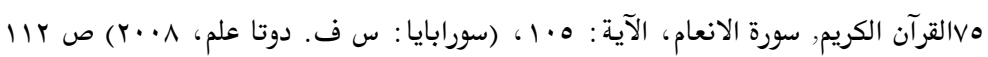

\section{'A Jamiy, Jurnal Bahasa dan Sastra Arab Volume 06, No. 2, September 2017}




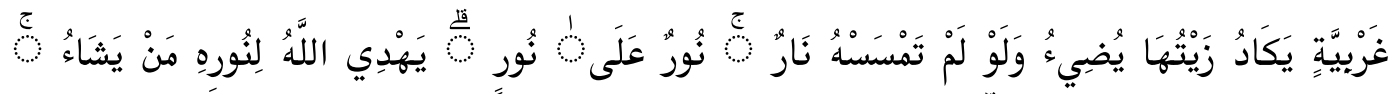

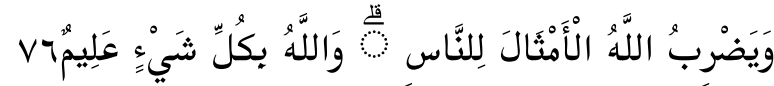
قال شيدلة في (البرهان) الدرى المضيء بالحبشية.

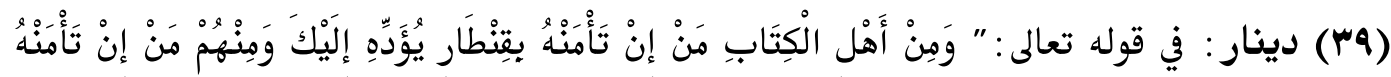

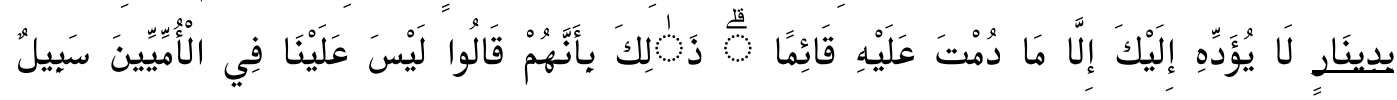

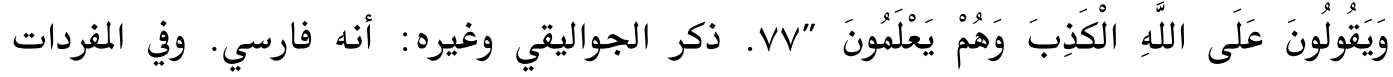
للراغب: (قيل أصله بالفارسية دين آر) الشريعة جاءت به. ذكر الجواليقي وغيره: أنه فارسي. وفي المفردات للراغب : (قيل أصله بالفارسية دين آر) الشريعة جاءت به.

في اللسان: الدينار: فارسي معرب, وأصله دنار, بالتثديد بدليل قولهم دنانير ودنينير فقلبت إحدى النونين ياء لئلا يلتبس بالمصادر التي تجيء على فقال, كقوله تعالى : (وكذبوا بئايتنا كذابا), إلا أن يكون بالهاء فيخرج على أصله, مثل: الصنارة: لأنه أمن الان من الالتباس, ولذلك جمع على دنانير, وثله قيراط وديباج وأصله دباج ...ورجل مدنر: كثير الدنانير. ودنر وجهه : أشرق وتلألأ كالدينار.

يقول الجو القي: و"الدينار": فارسي معرب. وأصله "دنار” وهو وإن كانمعربا فليس تعرف له العرب اسما غير “الدينار” فقد صار كالعربي.

ويقول السيوطي: ذكر الجو اليقي وغيره أن “الدينار”: فارسي. غير أن طوبيا العنيسي يرى أن دينار: لاتيني من ومعناه عشري, وهو نقد روماني قديم يشتمل على عشر وحدات, وكان الدينار عشرة دراهم عند العرب. دخل في اللغة العربية من الفهلوية , حيث مو افتته للفظ العربي

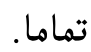
والجدير بالذكر أن الإنكليز يرمزون إلى البنس بحرف (اد) وهو الحقيقة أول حرف من كلمة أي الدينار.

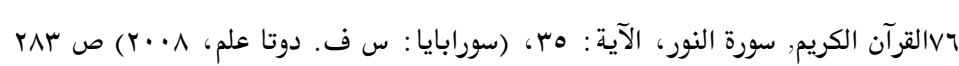

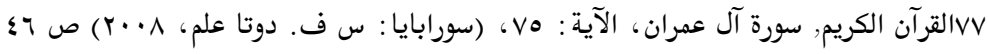

\section{'A Jamiy, Jurnal Bahasa dan Sastra Arab}




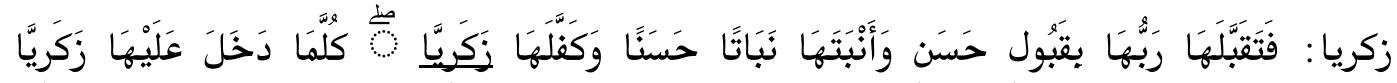

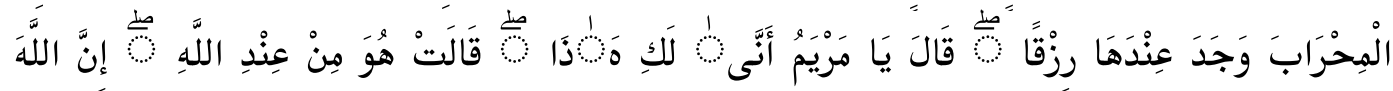

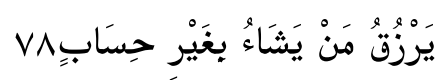

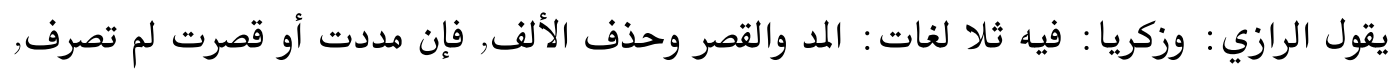

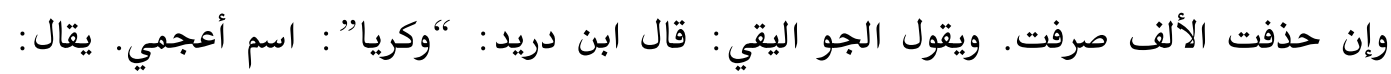

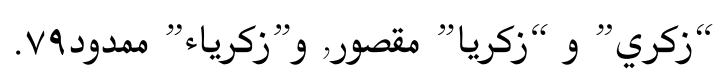

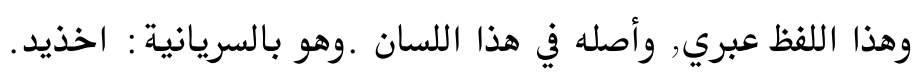

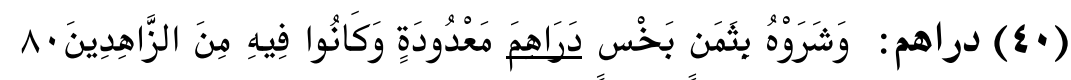
في اللسان: والدرهم والدرهم: لغتان, فارسي معرب. ملحق بيناء كلامهم, فدرهم كهجرع, ودرهم

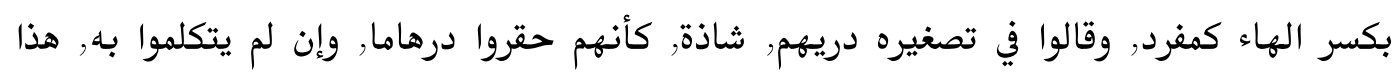
قول سيبوية. وجمع الدرهم: دراهم, ابن سيده: وجاء في تكسيره الدراهيم . يقول الجواليقي: و"درهم": معرب. وقد تكلمت به العرب قديما, إذنم يعرفوا غيره,

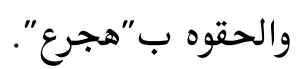
ويرى العنيسي أن "الدرهم" لفظ يوناني من drachme , وهو نقد فضة ووزن أيضا. ومنه "درم"

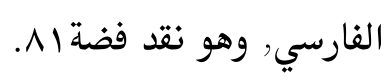
وفي قاموس الفارسية : الدرهم : وهو عملة قديمة معروفة وترد أيضا درهامبه. نقول: و"الدرهم” في

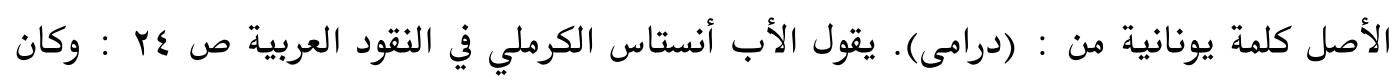

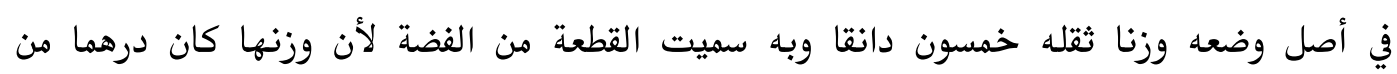
الفضة. كما أن الدينار مثقال من الذهب. وقد اختلفت قيمة الدرهم باختلاف الأزمان والبلدان. أ.ه.

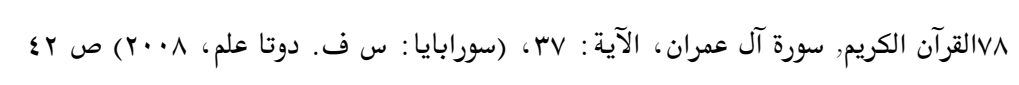

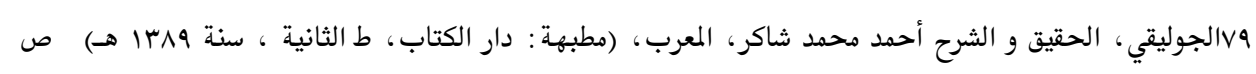

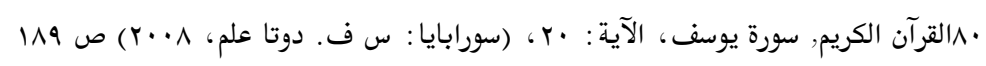

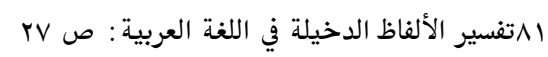

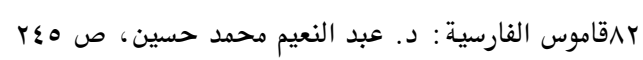

\section{'A Jamiy, Jurnal Bahasa dan Sastra Arab}

Volume 06, No. 2, September 2017 


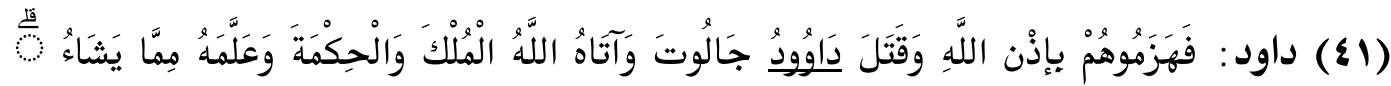

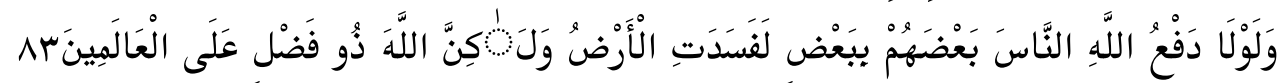

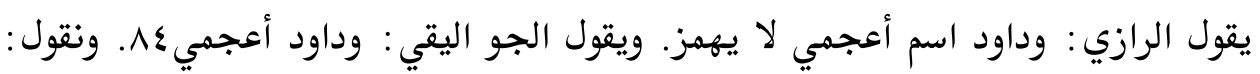
هو كلمة عبرية دخلت العربية من هذا اللسان.

المعرب هو الاسم الأعجمي أن تتفوه به العرب على منهاجها، تقول عرّبته العرب وأعرّبته

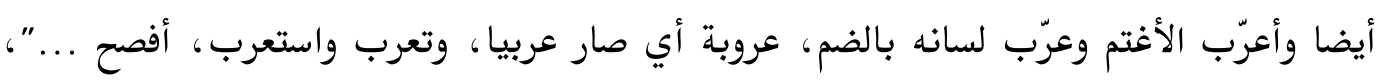

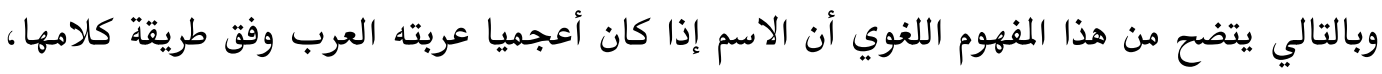

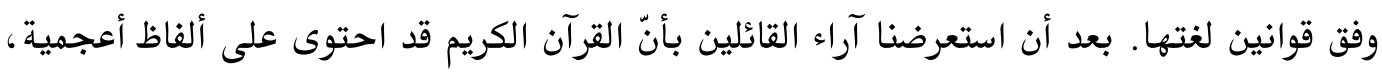

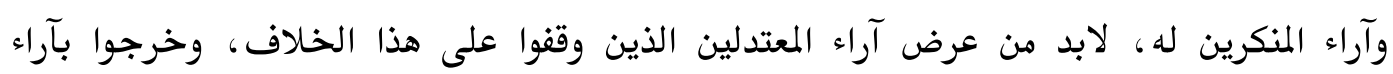

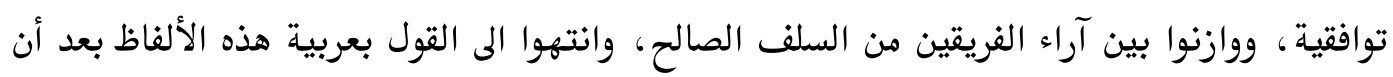

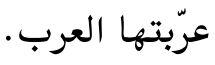

$$
\text { القرآن الكريم, (جاكرت : غما رسالة فريس، ه1911) }
$$

الأب رفاثيل نخله اليسوعي, غرانب اللغة العربية, (قاهرة: القلم، 1990)

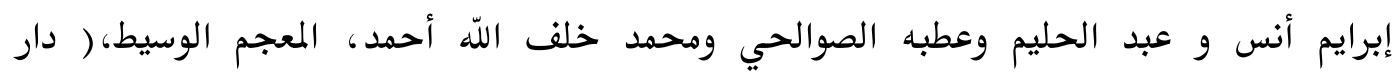

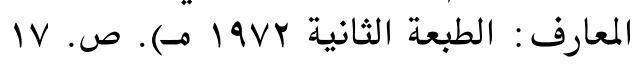

أبي بكر محمد بن القاسم الانباري النحوي، تحقيق محمد أبو الفضل إبراهيم ، لأضداد، (بيروت :

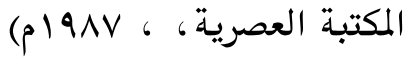

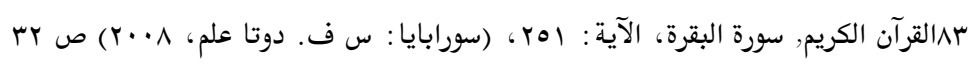

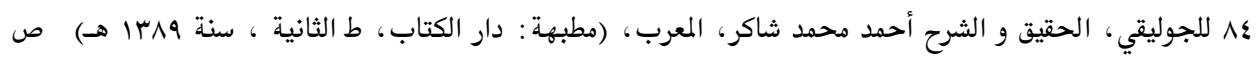

\section{'A Jamiy, Jurnal Bahasa dan Sastra Arab}


أبي منصور الجواليقي، المعرب في كلام الاعجمي علي حورف المعجم، (مطبعة دارالكتاب، سنة

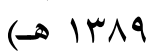

د. آرثر جفري، مقدمتان في علوم اللغة، (القاهرة: مكتبة الخانجي، طץ، بVY 1م.)

د. حلمي خليل، المولد في اللغة العربية، (بيروت: طج، دار النهضة ه191م) د. محمد حسن عبد العزيز، التعريب في القديم والحديث، (القاهرة: دار الفكر العربي.991م). د. محمود فهمي حجازي، علم اللغة لعربية (الكويت: دار الثقافة، سلوالم) رفائل نخلة اليسوعي، غرائب اللغة الربية، (ببيؤوت : الكاثوليكية، دون تارسخ) رمضان عبد التواب، فصول في فقه اللغة، (قاهرة: مكتبة الخانج، I9V9 ص : سجس . . الشيوطي ، المهذب فيما وقع في القرآن من المعرب، (قاهرة: الامانة . .ــاهـ) طوبيا العنيسي، تفسير الالفاظ الداخلة في اللغة العربية، (دار العرب للبيناني سىنة و949 هـ) عبد الرحمن عبد السبحان، المعرب والدخيل في اللغة العربية، (لبياء: دار المعارف، دون تاريخ) عبد القادر المغربي، الاشتقاق والتعريب،( مطبعة الهلال، ^•(9 م.) لأبي بكر محمد بن القاسم الانباري النحوي، تحقيق محمد أبو الفضل إبراهيم، الأضداد،

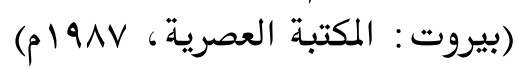

للامام محمد بن أبي بكر بن عبد القادر الرازي، مختار الصحاح (عيس البابي الحلبي: دون تاريخ

للجوليقي، الحقيق و الشرح أحمد محمد شاكر، المعرب، (مطبهة: دار الكتاب، ط الثانية ، سنة

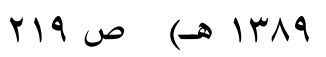

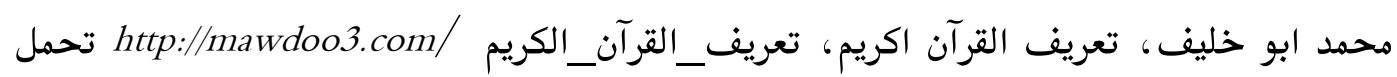

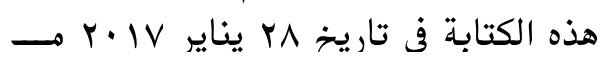

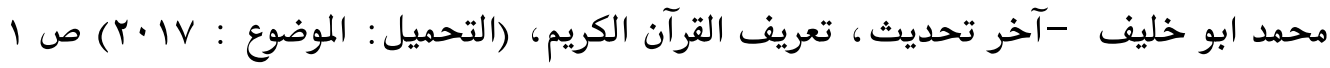

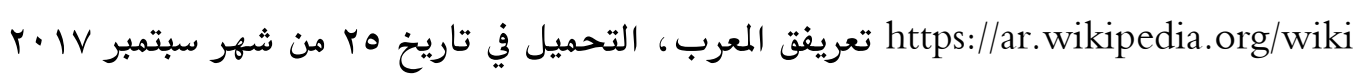

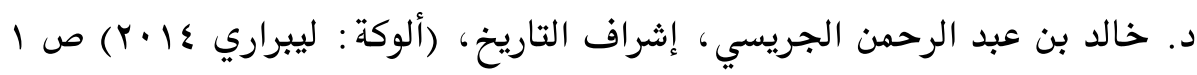

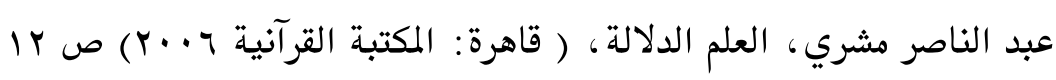
أبي الفضل جمال الدين محمد المصري، لسان العرب لابن منظور، (دار صادر بيروت: دون تاريخ) أحمد بن فارس، تحقيق زهير بن محسن، مجمل اللغة، (طץ، مؤسسة الرسالة : 1919)

\section{'A Jamiy, Jurnal Bahasa dan Sastra Arab Volume 06, No. 2, September 2017}

